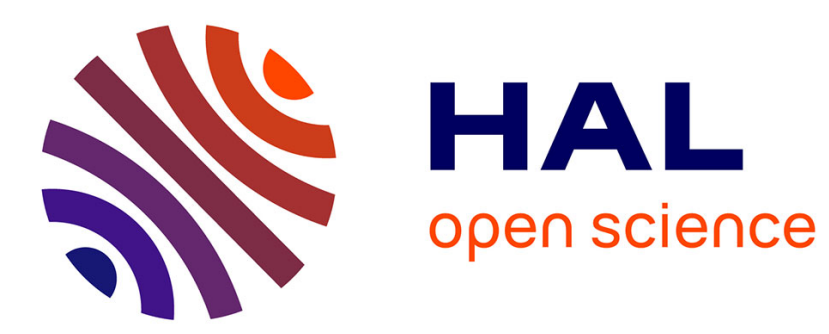

\title{
Dissolution Anisotropy of Pyroxenes: Role of Edges and Corners Inferred from Stochastic Simulations of Enstatite Dissolution
}

\author{
Arnaud Bouissonnié, Damien Daval, Philippe Ackerer
}

\section{- To cite this version: \\ Arnaud Bouissonnié, Damien Daval, Philippe Ackerer. Dissolution Anisotropy of Pyroxenes: Role of Edges and Corners Inferred from Stochastic Simulations of Enstatite Dissolution. Journal of Physical Chemistry C, 2021, 125 (14), pp.7658-7674. 10.1021/acs.jpcc.0c11416 . hal-03389765}

\section{HAL Id: hal-03389765 https://hal.science/hal-03389765}

Submitted on 22 Oct 2021

HAL is a multi-disciplinary open access archive for the deposit and dissemination of scientific research documents, whether they are published or not. The documents may come from teaching and research institutions in France or abroad, or from public or private research centers.
L'archive ouverte pluridisciplinaire HAL, est destinée au dépôt et à la diffusion de documents scientifiques de niveau recherche, publiés ou non, émanant des établissements d'enseignement et de recherche français ou étrangers, des laboratoires publics ou privés. 


\title{
1. Dissolution Anisotropy of Pyroxenes: Role of Edges and Corners Inferred from Stochastic Simulations of Enstatite Dissolution
}

\author{
3 Arnaud Bouissonnié,* Damien Daval, and Philippe Ackerer
}

Cite This: https://doi.org/10.1021/acs.jpcc.0c11416 Read Online

4 ABSTRACT: Experimental studies exhibit a wide variety of dissolution 5 rates for a given mineral depending on the chemical conditions and also 6 on the type of experiment conducted. As a relevant example, studies 7 focused on face-specific dissolution and those focused on powder 8 dissolution can present differences of up to 1 order of magnitude. 9 Linking these two types of experiments is therefore relevant, since 10 experimental conditions can be almost entirely controlled throughout 11 the entire experiment. In this study, we use a stochastic dissolution 12 model based on hydrolysis of atomic bonds of enstatite, the magnesium 13 endmember pyroxene, to simulate the dissolution of different sizes and 14 aspect ratios of enstatite grains. This model, validated in a previous 15 study by a comparison with experimental (face-specific) rate data, is 16 used to understand the evolution of the dissolution rate with time, from

17 the beginning of the dissolution until the entire consumption of the crystal. We show that the behavior of the dissolution is 18 controlled mainly by the aspect ratio of the grain. A simple dissolution model based on face-specific dissolution is then used to 19 compare the results of the simulations obtained with those resulting from the grain dissolution model. The similarity between the 20 results points out that the contribution to the dissolution of edges and corners is only modest for very anisotropic silicates such as 21 pyroxenes, where silicate tetrahedrons are connected through chains running parallel to a given crystallographic axis. This simple 22 model is then extended using both face-specific experimental and model results and compared to existing powder dissolution results. 23 This comparison shows an excellent agreement between face-specific dissolution modeling and powder dissolution experiment, 24 indicating that, for anisotropic minerals such as pyroxenes, face-specific and powder dissolution experiments can be linked, which can 25 be of great interest for future dissolution studies.

\section{INTRODUCTION}

26 Dissolution kinetics is a key parameter to understand the Earth's 27 surface evolution and is crucial for several industrial and 28 environmental problems (cement dissolution, nutrient deple29 tion in soils, etc.). Over the last decades, numerous studies have 30 helped understand the processes that occur at the mineral31 water interface, as well as developing different methods to 32 measure their kinetics for a wide variety of minerals. ${ }^{1-9}$ While 33 most of these studies are based on powder dissolution 34 experiments, ${ }^{2,10-12}$ fewer studies succeeded to measure 35 dissolution rates on different faces of a given miner36 al. $3,4,6,7,9,13-16$ This latter kind of studies has shown the 37 importance of the crystallographic structure (i.e., anisotropy) 38 on mineral dissolution kinetics. As a relevant example, 39 pyroxenes, which are strongly anisotropic due to their silica 40 tetrahedron chains, exhibit a strong dissolution anisotropy 41 consistent with the periodic bond chain theory. ${ }^{17}$ However, the 42 comparison between the dissolution rates measured on single 43 faces and those measured on powder highlights a significant 44 difference (powder dissolution rates are generally higher than 45 face-specific dissolution rates ${ }^{18}$ ). This adds complexity to our ability to upscale dissolution rates and to apply experimental 46 measurements on field studies without using empirical scaling 47 parameters that complicate reactive-transport simulations. $\quad 48$

As suggested by different studies, this difference may result 49 from the amount of reactive sites present in each case. ${ }^{19-23} 50$ Indeed, considering face dissolution often means considering a 51 reactive surface which is not affected by the dissolution of 52 mineral's edges and corner. However, not only these sites are the 53 most reactive, as shown in Noiriel et al., ${ }^{24,25}$ they are also present 54 in greater proportions in powders than on centimeter-sized 55 single crystals (if one assumes a flat surface at the beginning of 56 the experiments). Therefore, studying the contribution of these 57 corners and edges to dissolution is essential. To do so, new 58

Received: December 23, 2020

Revised: March 27, 2021 
Kossel crystal / Calcite

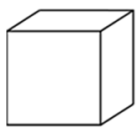

$\mathrm{t}=\mathbf{0}$

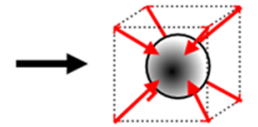

Site specific dissolution
Inosilicates / OrthoEnstatite

Site specific dissolution?

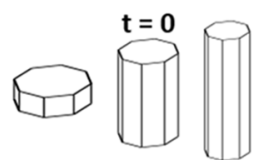

Effect of the aspect ratio?
Tre

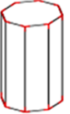

Face controlled dissolution?

Effect of the aspect ratio?

Figure 1. Schematic representation of the objectives of this paper. Dissolution is often assumed to take place on reactive sites such as edges and corners. It has been demonstrated on Kossel crystal and calcite that, during the dissolution process, the shape of the crystal evolves, and edges and corners are rounded, leading to an almost spherical shape (for Kossel crystal, depending on the activation energy of the hydrolysis) when the primal material is a cube. In this study, we aim to determine whether these considerations are applicable on inosilicates, with a specific focus on enstatite. The study is based on simulations using a stochastic dissolution model applied at the atomic bond level and aims to explore different aspect ratios of the initial mineral parallelepipedal shape.

59 experimental setups have emerged, using analytical techniques 60 such as X-ray tomography ${ }^{24-26}$ or vertical scanning interferom61 etry. ${ }^{27}$ However, despite their increasing efficiency to study the 62 processes that occur at finer scales (micrometer to nanometer 63 scale), they often need to be combined with numerical studies to 64 unravel what happens at the solid-fluid interface.

65 Numerical experiments have become a powerful tool to 66 improve our understanding of processes occurring at the water67 mineral interface, ranging from molecular dynamics to reactive68 transport model used at pore scale. ${ }^{28-30}$ The last decades have 69 also seen the development of stochastic dissolution models, such 70 as kinetics Monte Carlo models or Voronoi method. ${ }^{13,19,23,31-38}$ 71 These models, based on a relation between the activation 72 energies of individual processes (bond hydrolysis, for example) 73 and their occurrence probability, allow for fast computation and 74 the simulation of larger objects, which classical molecular 75 dynamics is not able to deal with. These models, first applied on 76 Kossel crystals, have brought or validated many important 77 results. As an example, numerous studies applied on Kossel 78 crystals validate the difference of reactivity between the crystal's 79 edges, corners, and surfaces. ${ }^{19}$ The work of Zhang and Luttge ${ }^{35}$ 80 also mentioned these differences for feldspar dissolution. 81 However, providing a generalization to other minerals, which 82 is an intrinsic issue belonging to the field of physical chemistry, is 83 important and may present a great interest to link laboratory and 84 field observations, as mentioned by Noiriel et al. ${ }^{25}$

85 For several reasons, pyroxenes represent a relevant target to 86 address these aspects. Indeed, not only do they have a strongly 87 anisotropic structure (silica chains running parallel to a given 88 crystallographic axis), but they are also present worldwide and 89 represent a major group of minerals for reactive-transport 90 models. $^{39,40}$ In two previous studies, ${ }^{16,41}$ we described a 91 stochastic dissolution model operating at atomic scale and 92 applied to enstatite, the magnesian endmember of pyroxenes. 93 This model, validated by a comparison between simulations and 94 experimental results, has shown its ability to reproduce the 95 dissolution anisotropy of enstatite as well as the surface features 96 observed at the end of the experiments (etch pit morphology, 97 and relative thickness of the silica layers developed on each 98 face). ${ }^{16}$ However, in these two studies, we focused on face99 specific dissolution, neglecting the contribution of "macro100 corners" and "macro-edges", which can represent, for some 101 minerals such as calcite, the most reactive sites. ${ }^{25}$ In the present 102 study, we propose to simulate the dissolution of enstatite 103 rectangular parallelepipeds. Different sizes and aspect ratios are modeled and analyzed, to understand if the dissolution of 104 enstatite grains can be described mathematically using 105 parameters related to the grain dimensions, as well as to 106 understand if observations made on calcite ${ }^{25}$ are expandable to 107 enstatite, and more generally, to pyroxenes. Another objective 108 deals with the impact of the aspect ratio of a grain on the 109 dissolution rate. Powder experiments present a wide variety of 110 grain morphologies resulting from the crushing of macro- 111 crystals. These different shapes and sizes may affect the 112 dissolution rate, since the dissolution rate is face-specific. ${ }^{3,15,16} 113$ Furthermore, different grain sizes may imply a greater rate 114 variability through the development of fast dissolving micro- 115 facets at mineral's edges and corners. These questions are 116 summarized in Figure 1.

\section{METHODS}

2.1. Model Description. A complete description of the 118 model is given in Bouissonnié et al. ${ }^{16}$ Briefly, atoms contained in 119 the enstatite cell are placed using $\mathrm{Pbca}$ space group symmetry 120 elements, using the cell parameters $(a=18.233 \AA, b=8.8191 \AA$, 121 and $c=5.1802 \AA$ ) and the coordinates given by Hugh-Jones and 122 Angel. ${ }^{42}$ Each magnesium and silicon atom is linked to oxygen 123 according to their coordination. However, the dissolution of 124 oxygen atoms is never considered in the dissolution model. 125 Indeed, they are considered as bridging atoms ${ }^{13}$ and the 126 dissolution model is applied on $\mathrm{M}-\mathrm{O}_{\mathrm{br}}-\mathrm{M}$ bonds ( $\mathrm{M}$ being a 127 $\mathrm{Mg}$ or $\mathrm{Si}$ atom). All atoms linked to another one via a bridging 128 oxygen are part of its first coordination sphere. ${ }^{13}$ Only the first 129 coordination sphere is taken into account to compute the bond- 130 breaking probabilities, since previous results showed that this 131 strategy results in a satisfactory agreement between modeled and 132 experimental results. ${ }^{16}$

Usually, the probability attributed with one event (i.e., the 134 bond-breaking probability) is written as follows ${ }^{38}$

$$
P=\mathrm{e}^{-E_{\mathrm{a}} / k_{\mathrm{B}} T}
$$

where $P$ stands for the bond-breaking probability, $E_{\mathrm{a}}$ is the 137 activation energy of the bond hydrolysis $(\mathrm{J}), k_{\mathrm{B}}$ is the Boltzmann 138 constant $(\mathrm{J} / \mathrm{K})$, and $T$ is the temperature $(\mathrm{K})$. In the present 139 study, the greatest bond-breaking probability (i.e., the bond 140 hydrolysis associated with the lowest activation energy, $\mathrm{Mg}-\mathrm{O}-141$ $\mathrm{Mg}$ ) was arbitrarily set to 0.99 and the two other probabilities 142 were scaled according to the differences between their 143 corresponding activation energies following 


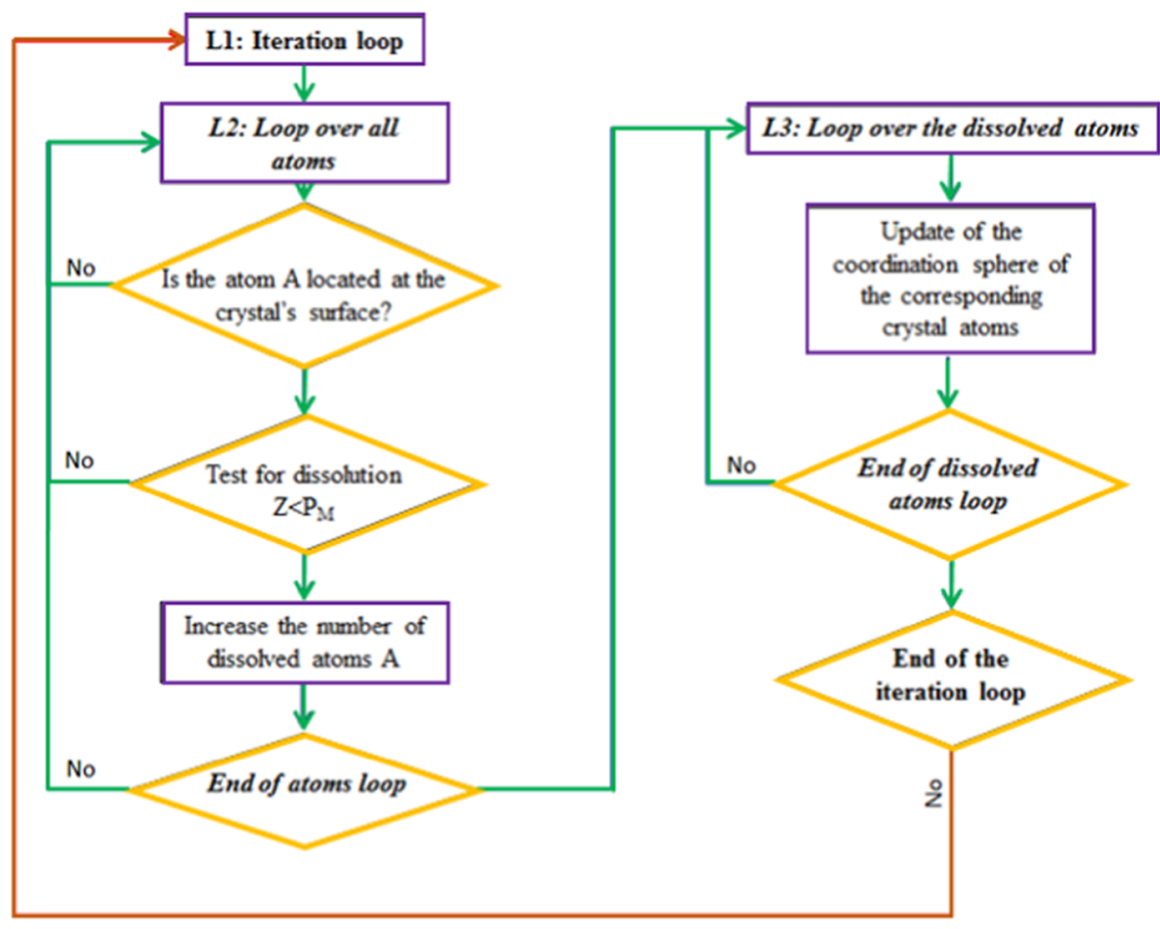

Figure 2. Scheme of the dissolution algorithm used in the dissolution model. This scheme is adapted from Bouissonnie et al. ${ }^{41}$

$$
145 \frac{P_{\mathrm{A}}}{P_{\mathrm{B}}}=\mathrm{e}^{-\left(E_{\mathrm{a}}^{\mathrm{A}}-E_{\mathrm{a}}^{\mathrm{B}}\right) / k_{\mathrm{B}} T}
$$

146 where A and B represent two different bonds. According to the 147 best agreement between modeled and experimental results 148 developed in Bouissonnie et al., ${ }^{16}$ the other two probabilities 149 were calculated as 0.4 and 0.0146 for $\mathrm{Mg}-\mathrm{O}-\mathrm{Si}$ and $\mathrm{Si}-\mathrm{O}-\mathrm{Si}$, 150 respectively. The probability of backward reactions (i.e., the 151 creation of a new bond, previously destroyed or not) is not 152 considered here since the model is applied to reproduce 153 experiments run at $\mathrm{pH} 0,{ }^{16}$ where these reactions can be 154 neglected.

155 As it has been shown to successfully reproduce experimental 156 data and observations, an "all-or-none" approach was used in 157 this study. ${ }^{13,19,35-37,43,44}$ This approach considers that an atom 158 is released only if all bonds that connect it to the surface are 159 simultaneously broken during a single iteration step. Hence, the 160 numerical model works directly on the atoms, and not on the 161 bonds. Then, the overall probability of an atom to be released 162 into solution during one iteration is given by the product of all of 163 the probabilities corresponding to the different bonds it shares 164 with other atoms

$$
P_{\mathrm{M}}=\mathrm{e}^{-n E_{\mathrm{M}-\mathrm{O}-\mathrm{Mg}} / k_{\mathrm{B}} T} \mathrm{e}^{-m E_{\mathrm{M}-\mathrm{O}-\mathrm{Si}} / k_{\mathrm{B}} T}=P_{\mathrm{M}-\mathrm{O}-\mathrm{Mg}}^{n} P_{\mathrm{M}-\mathrm{O}-\mathrm{Si}}^{m}
$$

165

166 where $n$ and $m$ stand for the number of bonds that the 167 considered atom shares with neighboring $\mathrm{Mg}$ and $\mathrm{Si}$ atoms, 168 respectively.

169 2.2. Dissolution Algorithm. At each iteration step, all 170 atoms located at the surface are scanned. An atom is considered 171 at the surface if its first coordination sphere is incomplete. A 172 random number $Z$ is generated for each atom; if $Z<P_{M}$, the 173 atom is released into the solution, if not, the scan of the atoms 174 moves on. At the end of the iteration, i.e., after scanning all atoms 175 located at the surface, the attributes of the atoms contained in 176 the first coordination sphere of those which have been dissolved during the iteration, are updated to consider this change, 177 resulting in an increase of their departure probability at the next 178 iteration. It is essential to update the attributes of the considered 179 atoms only at the end of an iteration to avoid an "in cascade" 180 dissolution, where the atoms would be released one after the 181 other due to a direct change of the probabilities. A scheme of the 182 algorithm is shown in Figure 2.

2.3. Output of the Model. The dissolution was monitored 184 based on the release of Si atoms, as in classical studies dedicated 185 to silicate dissolution kinetics. Note that because the dissolution 186 at steady state (i.e., the dissolution rate can be considered to be 187 constant) is stoichiometric, ${ }^{16}$ this choice has no consequence on 188 what will be described in the present study. However, the 189 behavior of $\mathrm{Mg}$ release is important at the beginning of the 190 dissolution process ${ }^{16}$ and will be discussed in the section 191 corresponding to this part of the dissolution timeline. 192

In the literature, the term "mineral dissolution rate" is usually 193 used to refer to the release rate of atoms in the solution from a 194 mineral surface, whether or not it is normalized to the contact 195 surface between the fluid and the mineral. To avoid any 196 confusion, in the following, we will use the term "dissolution 197 rate" to refer to a velocity that is not normalized to the surface 198 area (unit: mol/iteration) and "dissolution flux" to refer to 199 dissolution rates normalized with respect to the surface area 200 (unit: $\mathrm{mol} / \mathrm{m}^{2} /$ iteration). Both quantities are calculated at each 201 iteration for any numerical simulation.

202

The cumulated number of released atoms has been used to 203 calculate the total surface retreat during the simulations 204 corresponding to the dissolution of single faces (i.e., only one 205 face is considered to be in contact with the solution). The 206 surface retreat is defined as the average height of material lost 207 during the dissolution. It is calculated as follows 208

$$
\Delta h_{i}^{(h k l)}=\frac{a^{*} b^{*} c}{16^{*} S_{\mathrm{f}}} \sum_{i}^{n=1} n b\left(\mathrm{Si}_{d, n}\right)
$$



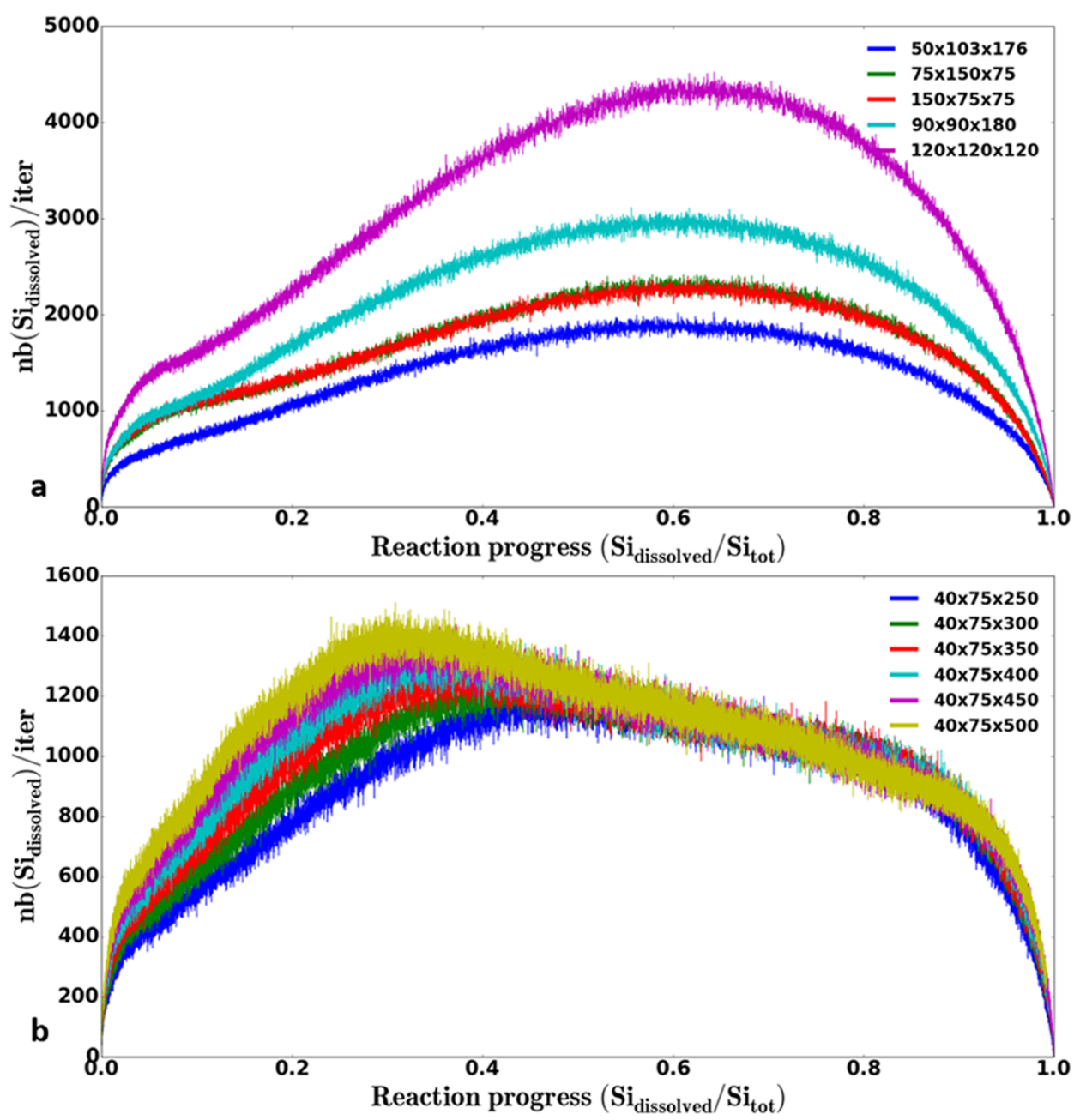

Figure 3. Results of the dissolution model showing the dissolution rate (defined as the number of Si atoms released per iteration) as a function of the reaction progress. Legends indicate how many times the crystal cell is multiplied in $x, y$, and $z$ directions. The results reported here represent sets of simulations applied on arbitrary parallelepiped sizes (i.e., not representative of the aspect ratio of natural enstatite). (a) First subgroup of simulations, with arbitrary rectangular parallelepiped dimensions. (b) Second subgroup: Length and width (parallel to the $a$ and $b$ axes of the enstatite cell) of the rectangular parallelepiped were kept constant while the height (parallel to the $c$ axis) was modified in the different simulations. In both cases, a similar behavior is observed. (a) Simulations highlight a parabolic behavior of the dissolution. The maximum seems to be observed at similar values of the reaction progress. (b) Contrary to the first set, the simulations of the second set are different at the beginning of the dissolution. Here, the larger the crystal, the higher the maximum. After reaching the maximum, the number of Si atoms dissolved decreases linearly. The slope is the same for each simulation.

210 where $\Delta h_{i}^{(h k l)}$ is the surface retreat at the ith iteration $(\mathrm{m}) ; a, b$, 211 and $c$ are the cell parameters $(\mathrm{m}) ; S_{\mathrm{f}}$ is the surface area of the face $212\left(\mathrm{~m}^{2}\right)$; and $n b\left(\mathrm{Si}_{d, i}\right)$ is the number of $\mathrm{Si}$ atoms dissolved at the $i$ th 213 iteration. The number 16 corresponds to the number of Si atoms 214 in the enstatite cell. This method has been validated in 215 Bouissonnié et al. ${ }^{16}$ and gives identical results to those obtained 216 if the mean coordinates in the direction normal to the surface 217 were used.

218 Finally, the last parameter used in this study is the 219 advancement of the dissolution reaction. It is defined as the 220 ratio between the number of $\mathrm{Si}$ atoms dissolved from the 221 beginning of the simulation and the initial number of $\mathrm{Si}$ atoms at 222 the beginning of the simulation.

223 2.4. Assumptions and Limitations of the Model. The 224 model has proven its ability to reproduce both experimental 225 dissolution rates and observed surface features evolutions. 226 However, several assumptions (all based on the studied 227 chemical condition) are considered and may impact the 228 model outputs and their upscaling to study natural environment:
- No backward reactions (i.e., formation of atomic bonds) 229 are implemented. This simplification was made because of 230 the very low $\mathrm{pH}$ of the studied solution $(\mathrm{pH} 0)$. This $\mathrm{pH} 231$ makes the solution to be very far from the thermodynamic 232 equilibrium with respect to enstatite. Therefore, backward 233 reactions (i.e., formation of atomic bonds) are considered 234 unlikely to happen.

- The dissolution algorithm is applied on atoms rather than 236 atomic bonds. This method is commonly used in 237 stochastic dissolution studies, however, combined with 238 the first assumption, this precludes the formation of 239 amorphous silica layers resulting from interfacial dis- 240 solution-reprecipitation $^{45}$ or reorganization of dangling 241 bonds. ${ }^{46}$ In the present study, such layers are suspected to 242 have no impact on the dissolution rate because their 243 passivating ability is thought to be $\mathrm{pH}$-dependent ${ }^{14,47}$ and 244 passivating layers are unlikely to form in strongly acidic 245 environments. Such conditions may limit the extension of 246 the conclusions of the study to less acidic environments. 247 


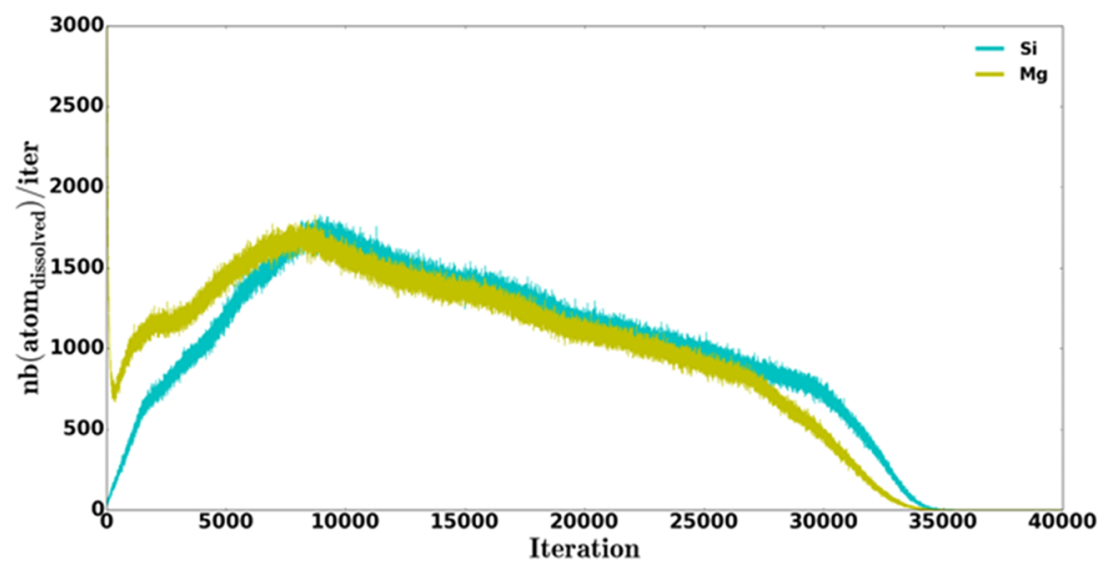

Figure 4. Example of the results of a simulation conducted on a $40 \mathrm{a} \times 82 \mathrm{~b} \times 700 \mathrm{c}$ volume. This figure shows the dissolution rate (number of dissolved atoms per iteration) as a function of the number of iteration steps. The cyan curve represents $\mathrm{Si}$ atoms, and the dark yellow curve represents $\mathrm{Mg}$ atoms. Contrary to the Si curve, which increases continuously at the beginning of the simulation, the $\mathrm{Mg}$ curve is marked by a sharp decrease of the number of atoms released per iteration. This is explained by the fast depletion of superficial $\mathrm{Mg}$, which have a high probability of departure. After reaching the maximum value of the amount of $\mathrm{Si}$ and $\mathrm{Mg}$ released per iteration (corresponding to the iteration where the silica layer reaches a constant thickness), the dissolution rate decreases continuously and the dissolution is stoichiometric.
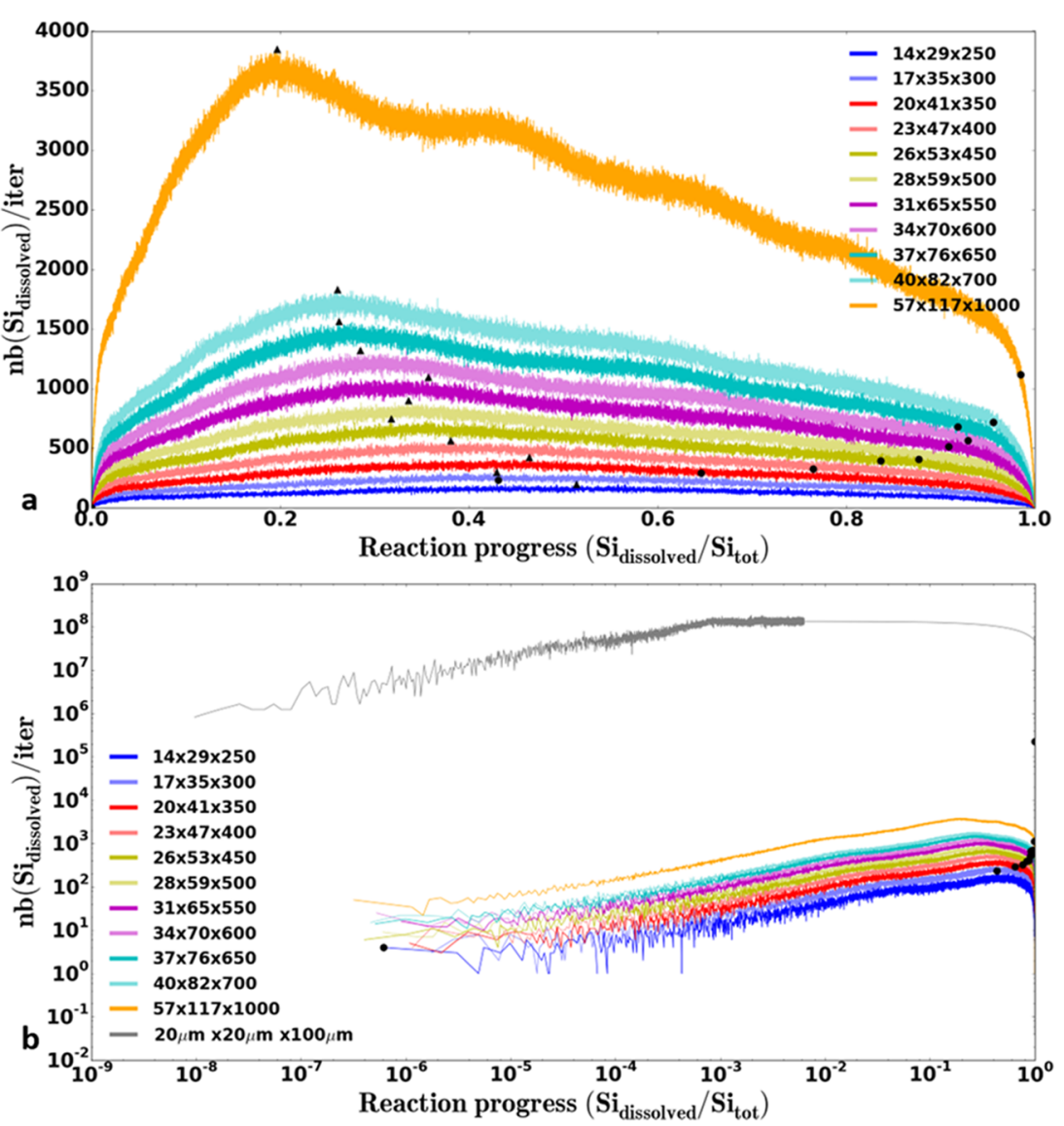

Figure 5. (a, b) Results of the dissolution model showing the dissolution rate (defined as the number of Si atoms released per iteration) as a function of the reaction progress. Legends indicate how many times the crystal cell is multiplied in $x, y$, and $z$ directions or exact dimension (black line). Each panel represents Si dissolution rate as a function of the reaction progress for the set of simulations that observe realistic aspect ratios for the grains, plotted in standard and logarithmic scales, respectively. Black triangles indicate the reaction progress where the dissolution rate reaches its maximum. Black circles indicate the reaction progress where the volume of the enstatite grain is equivalent to that of the initial smallest simulated rectangular parallelepiped $(14 \times 29 \times 250)$. For each simulation, the dissolution rate increases at the beginning of the process, until reaching Aconitum maximum value. After the maximum value is reached, the dissolution rate decreases linearly until the reaction progress reaches $\sim 95 \%$. The duration of the linear decreasing phase depends on the crystal size: the larger the crystal, the longer the linear phase.

However, the conclusions reached in the present study may remain valid even in conditions where the fluid is less acidic, as long as the fluid is at far from equilibrium with 250 respect to $\mathrm{SiO}_{2(\mathrm{am})}$, since presumptive passivating layers 251 
252 would be unstable and therefore, would not be rate253 controlling of the dissolution process. ${ }^{48}$

254 - The simulations correspond to conditions where the 255 aqueous solution is continuously stirred, resulting in no 256 local variations of the saturation index of the solution. 257 Therefore, the saturation index is supposed to be constant 258 (and far from equilibrium), both in space and time.

\section{RESULTS}

259 3.1. Evolution of Si Dissolution. A total of 22 different 260 enstatite volumes have been simulated. In the following, each 261 volume is named after the number of cells in the three spatial 262 directions.

263 The first 11 simulations were conducted using arbitrary 264 volumes to highlight potential similarities between their 265 dissolution behaviors. The results of these simulations are 266 given in Figure 3. This group of simulations can be separated 267 into two main subgroups (Figure 3a,b). The first subgroup 268 (Figure 3a) presents results of simulation runs with initial aspect 269 ratios that have no particular relation to each other, unlike the 270 second subgroup (Figure $3 \mathrm{~b}$ ), which contains simulations made 271 on grains varying only in height (the length in the $x$ and $y$ 272 directions having been kept constant).

273 The first subgroup is marked by a sharp increase of the 274 amount of dissolved $\mathrm{Si}$ atoms within the first 3-5\% of the 275 reaction, which corresponds to an increase from 0 to 500-1400 $276 \mathrm{Si}$ atoms released into solution per iteration, depending on the 277 initial volume. After this first step, the behavior of the release rate 278 of $\mathrm{Si}$ differs from the simulated volume. Indeed, while smaller 279 volumes $(50 \times 103 \times 176,75 \times 150 \times 75$ and $150 \times 75 \times 75)$ are 280 characterized by a linear increase extending over almost $40 \%$ of 281 the reaction, the others $(90 \times 90 \times 180$ and $120 \times 120 \times 120)$ 282 show a shorter linear evolution (only $20 \%$ of the total reaction). 283 In each case, after the linear increase of the release rate of Si into 284 solution, a slower increase is observed until the dissolution rate 285 reaches its maximum, which occurs after a similar reaction 286 progress (between 60 and 65\%) for all volumes of this subgroup. 287 The dissolution rate reaches $\sim 1900,2300,2300,2950$, and 4350 $288 \mathrm{Si}$ atoms/iteration for the $50 \times 103 \times 176,75 \times 150 \times 75,150 \times$ $28975 \times 75,90 \times 90 \times 180$, and $120 \times 120 \times 120$ volumes, 290 respectively. After this maximum is reached, the dissolution rate 291 of Si decreases until the reaction is complete, and all of the 292 crystal has been dissolved. This step extends over the last 35$29340 \%$ of the total reaction.

294 The second subgroup of simulations is composed of six 295 different volumes. While these volumes differ in height (length 296 in the $z$ direction parallel to the $c$ axis), the lengths in the $\mathrm{x}$ and $\mathrm{y}$ 297 directions were kept constant. Hence, the surface area of (100) 298 and (010) faces varied, unlike that of the (001) faces. The onset 299 of the simulations exhibits a similar behavior to that described 300 for the first subgroup: the first $3 \%$ of the reaction is characterized 301 by a sharp increase (from 0 to $350-600 \mathrm{Si}$ atoms/iteration) of 302 the release rate of Si. This step is followed by a linear increase of 303 the dissolution rate until it reaches its maximum. Contrary to the 304 first subgroup of simulations, the advancement corresponding to 305 this maximum depends on the size of the initial volume. Indeed, 306 if the maximal dissolution rate is greater for the largest volume $307(1390 \mathrm{Si}$ atoms/iteration for the volume $40 \times 75 \times 500)$ 308 compared to the smallest one ( $1190 \mathrm{Si}$ atoms/iteration for the 309 volume $40 \times 75 \times 250)$, the advancement at which the 310 maximum is reached is lower ( 0.30 against 0.45 , respectively). 311 Another difference between the first and second subgroups is the behavior of the dissolution after the maximum is reached. While, 312 in the first case, the dissolution rate decreases sharply until the 313 end of the reaction, in the second case, a slow and linear decrease 314 is observed from an advancement of $30-45$ to $85-90 \% 315$ depending on the considered volume. During this linear 316 decrease, regardless of the volume, all simulation results are 317 almost identical, showing the same dissolution rate of $\mathrm{Si}$ atoms at 318 the same advancement of reaction. The last $10-15 \%$ of the 319 reaction is characterized by a sharp decrease of the dissolution 320 rate of $\mathrm{Si}$ atoms to finally reach 0 when the reaction is complete 321 (Figure 4).

The second group of eleven simulations is shown in Figure 5. 323 f5 Contrary to the previous group of simulations, the aspect ratios 324 which were used are representative of natural enstatite crystal 325 habit. In spite of these differences, the evolution of the 326 dissolution rate of $\mathrm{Si}$ atoms is almost identical to that described 327 for the second subgroup of the first group described above, with 328 the following steps: (1) a sharp increase of the Si dissolution rate 329 during the first 3\% of the dissolution, (2) a linear increase until 330 the maximum is reached (from 145 to $3660 \mathrm{Si}$ atoms released 331 per iteration, reached after a reaction progress of $40-20 \%$ for the 332 smallest and the largest volumes, respectively), (3) a linear 333 decrease in the release rate of $\mathrm{Si}$ until $90-95 \%$ of the reaction, 334 and finally (4) a sharp decrease in the release rate of Si over the 335 last $5-10 \%$ of the reaction.

336

3.2. Evolution of $\mathbf{M g}$ Dissolution. The behavior of $\mathrm{Mg} 337$ dissolution is similar to the one described above for $\mathrm{Si} 338$ dissolution (Figure 4). The main differences are observed at 339 the very beginning and at the end of the simulations. Mg 340 dissolution evolution has been studied only for simulated 341 volumes representative of natural aspect ratios of enstatite. 342 Because all simulations, as for $\mathrm{Si}$ atoms, exhibit a similar 343 behavior, only one case is shown in Figure $4(40 \times 82 \times 700)$. 344 The global trend of $\mathrm{Mg}$ dissolution evolution is as follows: 345

- A dramatic decrease of the dissolution rate at the 346 beginning of the reaction ( 325 iterations for the volume 347 shown in Figure 4).

348

- An increase of the dissolution rate from the 315 th to the 349 8000th iterations. This increase is marked by two pulses 350 for the volume presented in Figure 4.

- A linear, slow decrease of the dissolution rate, similar to 352 the one observed in the case of Si dissolution. In the $40 \times 353$ $82 \times 700$ volume, this step extends from the 8000 th to the 354 26 990th iterations.

- A more pronounced decrease in the dissolution rate for 356 the last iterations until all of the $\mathrm{Mg}$ atoms have been 357 dissolved.

3.3. Dissolution Normalized Per Surface Unit. Because 359 the most realistic cases treated in this study are those that 360 observe the aspect ratio of pyroxenes, only the corresponding 361 simulations were investigated with respect to a normalization 362 per surface unit. The evolution of the surface area is not derived 363 from direct outputs of the simulations. Instead, it is assumed that 364 the surface decreases according to the retreat of each single face 365 of the simulated volumes. In Bouissonnie et al., ${ }^{16}$ we investigated 366 the surface retreat of (100), (010), and (001) faces, 367 demonstrating that our model was able to reproduce observed 368 experimental data. Similar simulations were then used to 369 calculate the evolution of the surface area of the simulated 370 crystals according to the following equation 

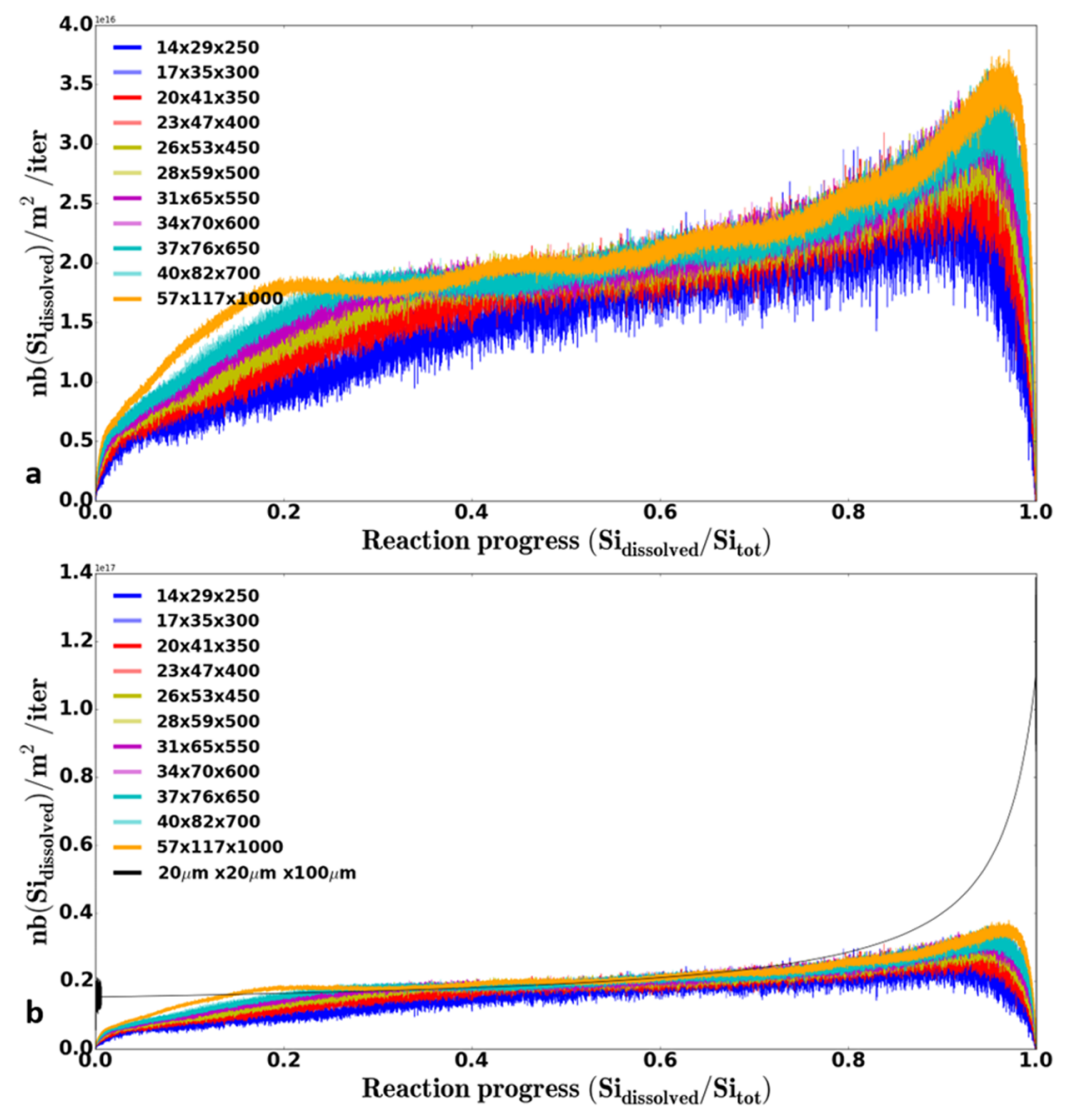

Figure 6. Dissolution flux as a function of the reaction progress. Legends indicate how many times the crystal cell is multiplied in the $x, y$, and $z$ directions. (a) Results of the simulations. (b) Results of the simulations and modeled theoretical result for enstatite grain with realistic grain size (black curve). The black patch at the beginning of the realistic grain size dissolution corresponds to the stages 1 and 2 of Figure 9a,b. In each case, the dissolution flux increases at the beginning of the simulations. After reaching a given value of the reaction progress (corresponding to the 8000th iteration), the increase slows down and the dissolution flux can be considered as constant for few iterations (the larger the crystal, the longer the "steady-state" regime). Then, a moderate increase is observed until the dissolution reaches its maximum. After reaching its maximum, the dissolution flux decreases dramatically and reaches zero when all of the atoms have been dissolved.

$$
\begin{aligned}
A(i)= & 2\left[\left(x_{0}-2 \Delta h_{i}^{(100)}\right)\left(y_{0}-2 \Delta h_{i}^{(010)}\right)\right. \\
& +\left(y_{0}-2 \Delta h_{i}^{(010)}\right)\left(z_{0}-2 \Delta h_{i}^{(001)}\right) \\
& \left.+\left(x_{0}-2 \Delta h_{i}^{(100)}\right)\left(z_{0}-2 \Delta h_{i}^{(001)}\right)\right]
\end{aligned}
$$

373 where $A(i)$ is the surface area at the $i$ th iteration; $x_{0}, y_{0}$, and $z_{0}$ are 374 the initial lengths in the $x, y$, and $z$ directions, respectively; and $375 \Delta h_{i}^{(h k l)}$ is the surface retreat of the corresponding $(h k l)$ face at 376 the ith iteration, derived from the simulations performed on 377 single faces where the edges were constrained to be nonreactive. 378 This method, however, does not take into account a possible 379 rounding of the edges, often observed in mineral dissolution 380 experiments and modeling. ${ }^{23,25,49}$ The number of $\mathrm{Si}$ atoms 381 released at each iteration is then divided by the surface area at 382 the corresponding iteration.

383 Results are shown in Figure 6. The trends followed by the 384 dissolution fluxes differ from those obtained for dissolution 385 rates. The first $3.5-1 \%$ of reaction is characterized by a sharp 386 increase in the dissolution flux from 0 to $5.4-6.2 \times 10^{15} \mathrm{Si}$ 387 atoms $/\left(\mathrm{m}^{2}\right.$ iteration $)$ for the smallest and largest volumes, 388 respectively. The increase in the dissolution flux is then less 389 pronounced over the next $42.5-19 \%$ of the reaction. The $\mathrm{Si}$ 390 dissolution flux reaches $1.6 \times 10^{16} \mathrm{Si}$ atoms $/\left(\mathrm{m}^{2}\right.$ iteration $)$ at $39147 \%$ of the reaction progress for the smallest volume against 1.8 $392 \times 10^{16} \mathrm{Si}$ atoms $/\left(\mathrm{m}^{2}\right.$ iteration $)$ at $20 \%$ for the largest one. After this period, the dissolution flux tends to stabilize for the three 393 largest volumes but only over a short reaction progress 394 (approximately 10\% of the total reaction). After this phase, 395 the dissolution flux of the largest volumes follows that of the 396 smallest ones. The dissolution flux still increases, but the 397 difference between each iteration is less pronounced until the 398 reaction progress reaches $90-96 \%$ (where the dissolution flux 399 reaches its maximum: $(2.2-3.5) \times 10^{16} \mathrm{Si}$ atoms $/\left(\mathrm{m}^{2}\right.$ iteration $) 400$ for the smallest and largest volumes, respectively). Finally, from 401 90 to $96 \%$ of the dissolution, the Si dissolution flux decreases 402 sharply to reach 0 when the volume has been completely 403 consumed.

\section{DISCUSSION}

4.1. Evolution of $\mathrm{Mg}$ and Si Dissolution Rates. 405 4.1.1. Evolution during the First 8000 Iterations. Despite the 406 differences in volumes used in the simulations, all simulation 407 outputs are characterized by a sharp increase of the number of $\mathrm{Si} 408$ atoms released at the beginning of the dissolution. Figures 3a 409 and $5 \mathrm{~b}$ show this increase as a function of the advancement of 410 the dissolution reaction. Depending on the volumes, the 411 advancements corresponding to this stage are different. 412 However, a clear pattern is highlighted when this evolution is 413 considered as a function of the number of iteration steps (i.e., 414 time) (Figure 7a). The dissolution rate is always at maximum $415 \mathrm{f} 7$ around the same iteration $(\approx 8000$ th $)$ for the different volumes. 416 

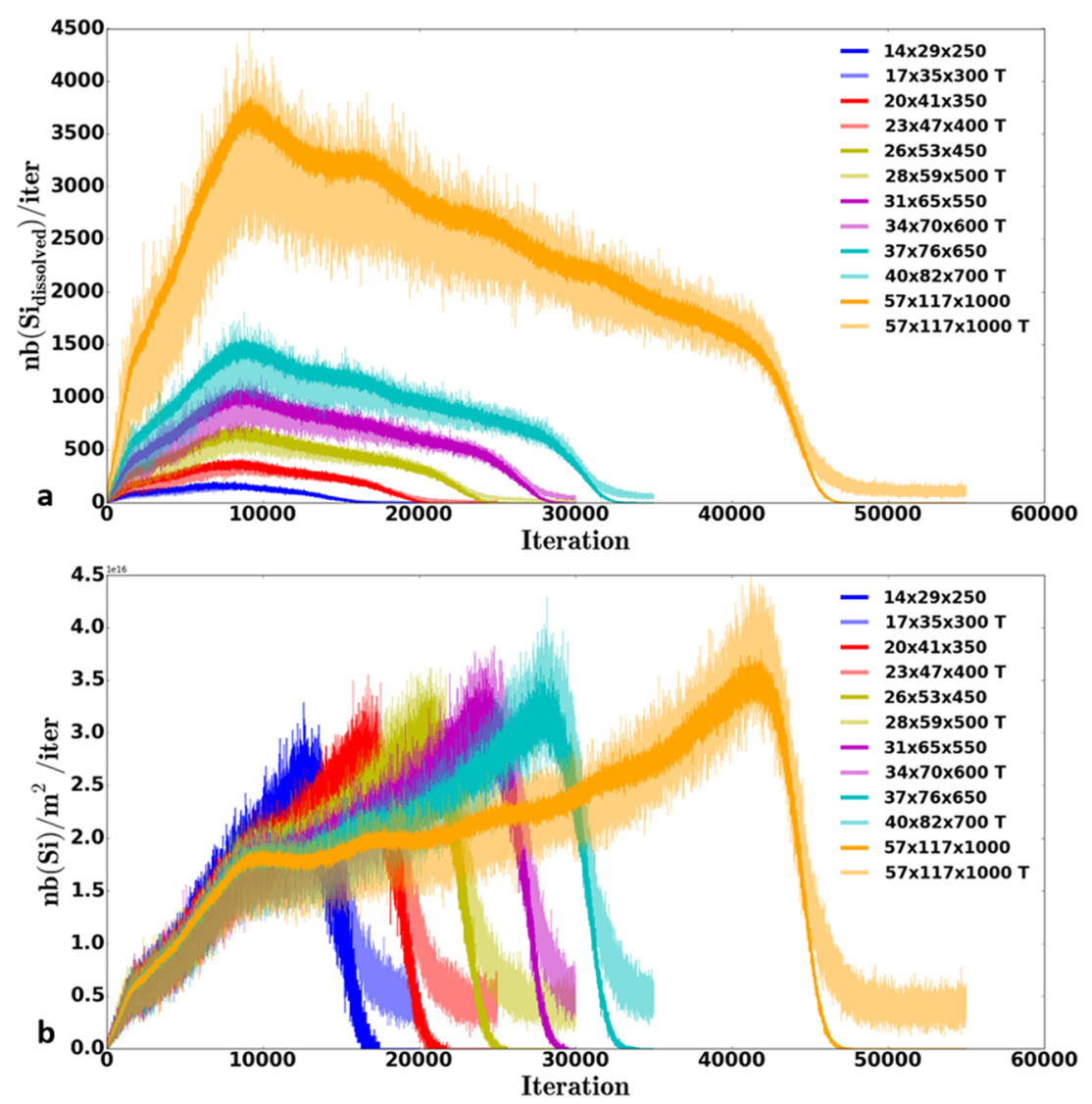

Figure 7. (a) Dissolution rate as a function of the total number of iteration steps (equivalent to time). Legends indicate how many times the crystal cell is multiplied in the $x, y$, and $z$ directions. Light-colored curves represent the evolution of the number of $\mathrm{Si}$ atoms released per iteration based on theoretical considerations developed in Section 4.2. Dark-colored curves represent the simulation results of the stochastic dissolution of rectangular parallelepipeds. (b) Dissolution flux as a function of the total number of iteration steps. Light-colored curves represent the evolution of the number of Si released per iteration and per surface unit based on theoretical considerations developed in Section 4.2. Dark-colored curves represent the simulation results of the stochastic dissolution of rectangular parallelepipeds. In each panel, the agreement between theory and simulation outputs highlights the slight effects of edges and corners on the global rate/flux. The difference between theory and simulation outputs at the end of the simulations is due to the assumptions underpinning the theoretical model (see text for details).

417 Interestingly, this value corresponds to the one where the surface 418 retreat of the (001) face reaches the steady state when the set of 419 probabilities used is $[0.99,0.4,0.0146]$ for $[\mathrm{Mg}-\mathrm{O}-\mathrm{Mg}, \mathrm{Si}-$ $420 \mathrm{O}-\mathrm{Mg}, \mathrm{Si}-\mathrm{O}-\mathrm{Si}]$ bonds respectively. ${ }^{16}$ It was interpreted as 421 the moment when the dissolution becomes congruent. 422 Considering that the other faces reach their steady-state 423 dissolution regime before the (001) face, ${ }^{16}$ the fact that the 424 dissolution rate of the simulated rectangular parallelepipeds is at 425 maximum at the iteration corresponding to the attainment of a 426 steady state for face (001) may mean that the evolution of the 427 dissolution regime of a simulated rectangular parallelepiped 428 enstatite is controlled by the face for which this steady state is 429 reached the latest (after the largest number of iterations). 430 Alternatively, another explanation could be that the face (001) 431 being the fastest to dissolve, the amount of Si released from this 432 face is greater than those of the other faces. Hence, this relation 433 between a simulated rectangular parallelepiped enstatite and the 434 (001) face reaching their steady state at the same iteration may 435 come from the fact that a significant proportion of their 436 dissolution is supported by the (001) face.

437 Regarding the dissolution rate of $\mathrm{Mg}$ atoms, Figure 4 shows 438 that it decreases dramatically during the first few hundred 439 iterations ( 325 for the volume $40 \times 82 \times 700$ ). This can be 440 explained by the fast departure of $\mathrm{Mg}$ atoms from the reactive 441 surface at the beginning of the simulations because of their greater probability to be dissolved. This results in a fast leaching 442 step at the beginning of the reaction, when these atoms are 443 numerous. After a few iterations, the main coordination of $\mathrm{Mg}$ at 444 the surface increases prior reaching a constant value, ${ }^{41}$ making 445 them more difficult to dissolve.

The fast decrease of $\mathrm{Mg}$ dissolution rate can also be linked to 447 the increase of $\mathrm{Si}$ dissolution rate. Indeed, the fewer the $\mathrm{Mg}-\mathrm{O}-448$ Si bonds, the higher the Si departure probability. In other words, 449 when numerous $\mathrm{Mg}$ atoms are released into solution, the 450 dissolution of $\mathrm{Si}$ atoms is enhanced. This departure of $\mathrm{Si}$ atoms 451 resulting from the fast leaching of $\mathrm{Mg}$ atoms at the surface also 452 makes it easier for the "solution" to reach the Mg atoms located 453 deeper in the simulated crystals. These combined effects 454 possibly explain why, after a dramatic decrease, the $\mathrm{Mg} 455$ dissolution rate increases with $\mathrm{Si}$ dissolution, until the maximum 456 is reached. After the maximum is reached, both $\mathrm{Si}$ and $\mathrm{Mg} 457$ dissolution rates decrease. More importantly, these decreases 458 are almost identical (same slope), indicating that the dissolution 459 is stoichiometric.

4.1.2. Parameters Controlling the Dissolution. Although the 461 first set of simulated rectangular parallelepipeds was not 462 representative of the aspect ratio of natural enstatite grains, ${ }^{50} 463$ it allows highlighting some behaviors and parameters that may 464 control the dissolution. Indeed, the two subgroups presented in 465 Figure 3 have their own patterns that can help understand the 466 

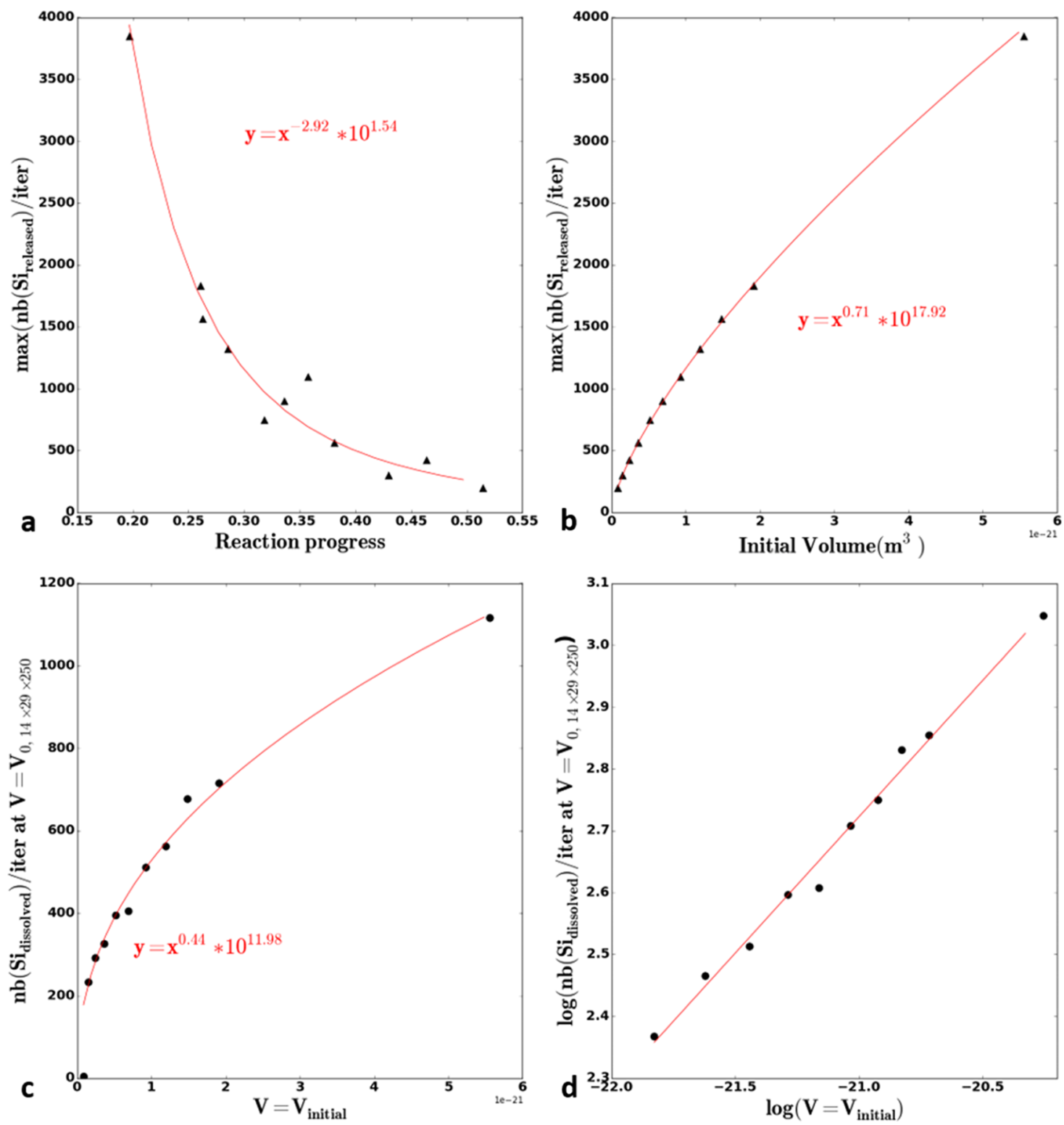

Figure 8. (a) Maximum dissolution rate as a function of the progress of the dissolution process for various initial volumes. Each triangle represents a different initial volume. The maximal value corresponds to the largest volume and the minimal to the smallest. (b) Maximum dissolution rate as a function of the initial volume. (c, d) Dissolution rate when the volume of the enstatite grain reaches the initial volume of the smallest simulated rectangular parallelepiped $(14 \times 29 \times 250)$ as a function of the initial simulated enstatite rectangular parallelepiped volume represented in standard and logarithmic scales, respectively.

467 two principal factors impacting the dissolution, namely, the 468 length of the rectangular parallelepiped in the $z$-direction and 469 the surface area of the (001) face. The most striking feature is the 470 one of the subgroup composed of rectangular parallelepipeds 471 varying only by their heights $(40 \times 75 \times 250,40 \times 75 \times 300,40$ $472 \times 75 \times 350,40 \times 75 \times 400,40 \times 75 \times 450$, and $40 \times 75 \times 500)$. 473 While the beginning of the dissolution differs depending on the 474 volume, the stage depicting a decreasing reactivity is 475 characterized by a similar trend and value of $\mathrm{Si}$ dissolution 476 rates for all simulations (Figure $3 \mathrm{~b}$ ). Therefore, it can be 477 assumed that this stage is controlled mostly by the surface area of 478 the (001) faces. Then, the surface area of the (100) and (010) 479 faces would only affect the reaction progress required to reach 480 this stage (the greater these surfaces, the longer the preliminary 481 stage).
This assumption can be verified with the second subgroup of 482 simulated rectangular parallelepipeds $(50 \times 103 \times 176,75 \times 150483$ $\times 75,150 \times 75 \times 75,90 \times 90 \times 180$, and $120 \times 120 \times 120)$. 484 Indeed, the only simulations presenting the same (001) surface 485 area are those conducted with the $75 \times 150 \times 75$ and $150 \times 75 \times 486$ 75 volumes. These two rectangular parallelepipeds have the 487 same dissolution behavior throughout the entire reaction 488 (Figure 3a). While this similarity supports that the dissolution 489 is primarily controlled by the face (001), it also suggests that the 490 other two faces have only a minor contribution to the overall 491 dissolution rate of enstatite grains. This is further supported by 492 the differences in reaction rates between the three faces $((100), 493$ (010), and (001)). The dissolution rate of the (001) face is more 494 than 1 order of magnitude higher than those of faces (100) and 495 (010). To have a significant impact on the total dissolution rates, 496 the surface area of the (100) and (010) faces should be at least 497 
49810 times greater than that of the (001) face, which was never 499 investigated in this study due to computational capacities and 500 our commitment to perform simulations that observe as much as 501 possible the aspect ratios of enstatite grains encountered in 502 natural environments.

503 The difference in shape between the released Si curves of the 504 two subgroups (Figure 3a vs Figure $3 b$ ) is more difficult to 505 explain. The main difference in the simulation parameters 506 resides in the dimensions of the simulated volumes and mainly, 507 their heights. Indeed, the heights (length in the $z$ direction) of 508 the subgroup composed of the $50 \times 103 \times 176,75 \times 150 \times 75$, $509150 \times 75 \times 75,90 \times 90 \times 180$, and $120 \times 120 \times 120$ rectangular 510 parallelepipeds are smaller than those of the volumes of the 511 second subgroup. It is therefore possible that the former 512 volumes are consumed before reaching a stage where the $\mathrm{Si}$ 513 dissolution rate decreases linearly, which would explain this 514 difference in behavior. If the overall dissolution is mainly 515 controlled by the dissolution of the (001) faces, it is indeed 516 possible that these volumes cannot reach this dissolution stage 517 because their height is too short. This is consistent with the 518 evolution of the dissolution rate of the other subgroup for which 519 the smaller the volume, the shorter the linear stage. It can be 520 reasonably assumed that rectangular parallelepipeds with a very 521 short height never reach a stage where the dissolution rate 522 decreases linearly.

523 To conclude, the simulations shown in Figure 3 provide 524 important information regarding the global dissolution of a 525 rectangular parallelepiped enstatite: the dissolution rate seems 526 mainly controlled by that of the (001) faces.

527 The simulations conducted with the second set of rectangular 528 parallelepipeds, more representative of the natural crystal habit 529 of pyroxenes, also exhibit specific patterns. Indeed, while the 530 amount of $\mathrm{Si}$ atoms released at each iteration varies from one 531 volume to another, trends and shapes are identical (Figure 5). 532 This could indicate that the overall evolution of the dissolution is 533 directly controlled by the shape of an enstatite grain. For the 534 same aspect ratio, the initial volume only influences the absolute 535 amount of released atoms.

536 This simulation set allows focusing on a quantity that 537 delineates a transition in the evolution of the dissolution rate 538 of a rectangular parallelepiped enstatite, namely, the maximum 539 value this latter can reach (black triangles in Figure 5a). While it 540 is obvious that the bigger the volume of a rectangular 541 parallelepiped, the greater the instantaneous $\mathrm{Si}$ dissolution 542 rate, interestingly, it is possible to link these two quantities 543 mathematically (Figure 8b). In the same way, it is possible to 544 link this maximum rate to the reaction progress (Figure $8 \mathrm{a}$ ). The 545 corresponding relations are given by

$$
\begin{aligned}
& \max \left(\mathrm{Si}_{\text {released }}\right)=10^{17.9} \times V_{0}^{0.71} \\
& \max \left(\mathrm{Si}_{\text {released }}\right)=10^{1.54} \times \xi^{-2.92}
\end{aligned}
$$

547 where $V_{0}$ is the initial volume $\left(\mathrm{m}^{3}\right)$ and $\xi$ is the reaction progress. 548 Combining these two relations allows predicting the reaction 549 progress corresponding to the maximal dissolution rate as a 550 function of the initial volume.

$$
551 \quad \xi_{\max (\mathrm{Si})}=10^{-5.61} \times V_{0}^{-0.24}
$$

552 Based on this equation, it is theoretically possible to estimate 553 the time at which the release of $\mathrm{Si}$ is maximal when knowing the 554 initial volume of an enstatite grain. Such empirical relations are 555 very relevant for experimental works and practical applications because it corresponds to the attainment of the steady-state 556 regime of the dissolution (see Section 4.5).

4.1.3. Variability of Dissolution Rates for a Given Grain 558 Size. A long-standing concern in mineral/water interaction deals 559 with the uniqueness of the dissolution rate. ${ }^{18,51}$ While the 560 variability of the dissolution rate is known to be significant when 561 the geochemical conditions are changed, it is often assumed, 562 particularly in reactive-transport studies, that the intrinsic 563 dissolution rate constant remains unchanged when the fluid 564 chemistry and the temperature are constant. However, several 565 studies tend to show that this assumption may be too simplistic, 566 as the dissolution rate may vary with time. While some studies 567 highlight a monotonic decrease of the dissolution rate with time 568 which can be associated with several factors such as the 569 development of amorphous silica-rich layers, ${ }^{52}$ others emphasize 570 a complex evolution of the dissolution rate resulting from the 571 gradual modification of the crystal habit, ${ }^{15,23,53}$ the inherited 572 history of the crystal reactivity ${ }^{54,55}$ or the microstructural 573 differences (e.g., defect density) between two individual crystals 574 of a same mineral. ${ }^{3,5,18,23,56-58}$ Therefore, it is central to 575 understand if two minerals placed under the same biogeochem- 576 ical conditions but differing in their history (one being fresh and 577 the other one being aged for example) will have the same 578 dissolution rate; hence, if two minerals of the same volume have 579 the same unique dissolution rate.

580

To investigate this question using the dissolution model, it has 581 been decided to focus on the dissolution rate of the rectangular 582 parallelepipeds when their volume reaches a volume equivalent 583 to that of the smallest simulated crystal $(14 \times 29 \times 250)$. The 584 remaining volume is calculated with the number of atoms that 585 are still in the rectangular parallelepiped at each iteration 586 following

$$
V_{i}=\frac{a^{*} b^{*} c}{16}\left(N_{0}-\sum_{i}^{n=0} N_{n}\right)
$$

with $V_{i}$ the volume at the ith iteration; $a, b$, and $c$ the cell 589 parameters $(\mathrm{m}) ; N_{0}$ the number of $\mathrm{Si}$ atoms in the enstatite 590 parallelepiped at the beginning of the simulation; and $N_{n}$, the 591 total number of $\mathrm{Si}$ released until the $i$ th iteration. This mass 592 balance is divided by 16 since the enstatite cell is formed by 16593 atoms of $\mathrm{Si}$. The attainment of the volume corresponding to the 594 smallest crystal is indicated by the black circles in Figure 5, and 595 the dissolution rates at $V=V_{14 \times 29 \times 250}\left(\right.$ named $S i_{\text {released, } V=V_{14 \times 29 \times 250}}{ }_{596}$ as a function of the initial volume are shown in Figure $8 \mathrm{c}, \mathrm{d} .597$ Interestingly, a relation between the initial volume and the 598 dissolution rates for $V=V_{14 \times 29 \times 250}$ exists

$$
\mathrm{Si}_{\text {released, } V=V_{14 \times 29 \times 250}}=10^{12.0} \times V_{0}^{0.44}
$$

This kind of relationships means that for a given volume, 601 different values of dissolution rates exist depending on the initial 602 size of the minerals.

603

4.2. Simple Mathematical Model of Si Dissolution 604 Rate. The evolution of Si dissolution rates and fluxes has a 605 specific behavior as described above. If this behavior seems 606 difficult to reproduce with a theoretical model, it is possible to 607 test hypotheses on how the dissolution evolves: here, we suggest 608 testing the assumption that the overall enstatite grain dissolution 609 simply corresponds to the sum of the contribution of the various 610 single faces delineating the enstatite volume. This assumption 611 may be true if, contrary to what is often proposed in the 612 literature, the edges and corners do not have a strong impact on 613 


\section{Kossel crystals}
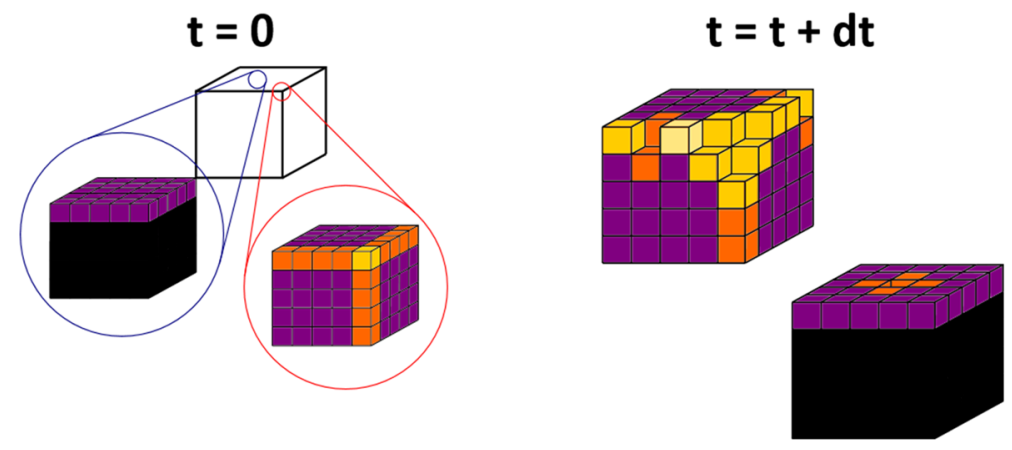

Enstatite crystals

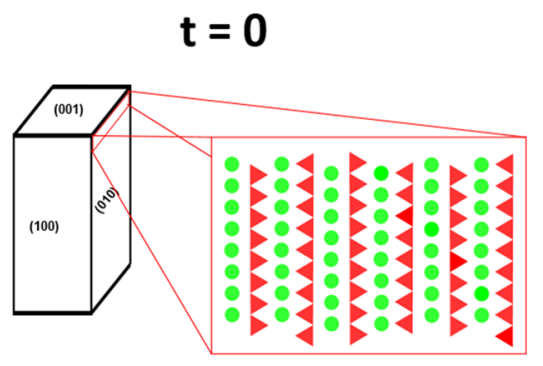

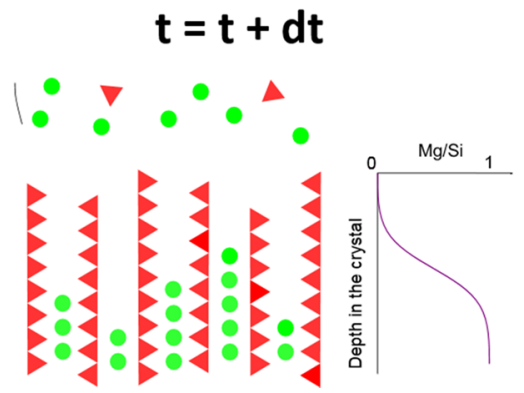

Figure 9. Scheme of the mechanism driving the dissolution of Kossel and enstatite crystals. Kossel: Black cubes represent atoms that are not at the mineral reactive surface. Purple, orange, and yellow cubes represent surface-, edge-, and corner-site atoms, respectively. During the dissolution, the atoms with fewer neighbors have a higher probability to be dissolved. This leads to the formation of rounded corners and edges. The atoms at the surface with only one neighbor missing (purple) are particularly difficult to dissolve compared to the others. Enstatite: at the beginning of the dissolution, $\mathrm{Mg}$ atoms are dissolved first. This is particularly visible on the (001) face where they exhibit a less populated first coordination sphere, leading to $\mathrm{Mg}$ depletion of the surface and the formation of a Si-enriched layer with a thickness not exceeding a few atomic layers. Because silica chains are not connected to each other, the probability of departure of Si atoms is the same on the entire (001) face, making it unlikely to exhibit rounded edges and corners.

614 the dissolution rate/flux and thus, if these sites do not lead to an 615 excessive rounding of the crystal. In this case, a simple cross616 multiplication would be able to reproduce the evolution of the 617 dissolution rate/flux.

618 To model the dissolution of $\mathrm{Si}$ atoms, the first step is to 619 consider the volume $\left(\Delta V_{i}\right)$ that is dissolved during an iteration

$$
\begin{aligned}
620 \Delta & V_{i}=V_{i-1}-V_{i} \\
V_{i} & =\left(x_{0}-2 \Delta h_{i}^{(100)}\right)\left(y_{0}-2 \Delta h_{i}^{(010)}\right)\left(z_{0}-2 \Delta h_{i}^{(001)}\right)
\end{aligned}
$$

622 If the dissolved volume is known, the number of Si atoms 623 released per iteration can easily be calculated knowing the 624 volume of the enstatite cell and the number of Si atoms it 625 contains (16)

$$
626 \mathrm{Si}_{\text {released }, i}=\frac{16 \Delta V_{i}}{a b c}
$$

627 Modeling the release rate of $S i$ requires to know the values of $628 \Delta h_{i}^{(h k l)}$ at each iteration step $i$, which requires to know the face629 specific dissolution rate of enstatite both at steady state and 630 during the transient states, i.e., at the beginning and at the end of 631 the simulations. To the best of our knowledge, while an 632 analytical expression has been developed in Bouissonnié et al. ${ }^{41}$ 633 for the steady state, a similar expression does not exist for 634 transient phases. To model the dissolution of the rectangular 635 parallelepipeds used in the different simulations, we first performed three additional face-specific simulations (i.e., 636 simulations where only the atoms belonging to the face $(h k l) 637$ are allowed to react, thus excluding atoms belonging to edges, 638 corners, and all other $\left(h^{\prime} k^{\prime} l^{\prime}\right)$ faces), with a depth equivalent to 639 half the depth of the volume in a given direction. The evolution 640 of the surface retreats as a function of time for the (100), (010), 641 and (001) faces were then retrieved and implemented in eq 10b 642 to model the dissolution of a rectangular parallelepiped and 643 determine the evolution of the release rate of $\mathrm{Si}$ atoms as a 644 function of time. The results of this dissolution model are 645 presented in Figure 7 (light-colored curves) and compared to 646 the outputs of the simulations conducted with rectangular 647 parallelepipeds (dark-colored curves). The agreement between 648 both models is striking, with a sharp increase of the dissolution 649 rate observed during the first 8000 iterations, followed by a slow 650 decrease of the dissolution rate and a sharper decrease at the end 651 of simulations.

652

4.3. Comparison between Results of the Simulation 653 and Modeled Dissolution. Figure 7 shows that the results 654 derived from theoretical dissolution and modeled dissolution 655 are almost identical. With the exception of the very end of the 656 dissolution, the results of the simulations performed with 657 rectangular parallelepipeds and those derived from face-specific 658 dissolution are superimposed. However, contrary to the results 659 of the simulations performed with rectangular parallelepipeds, 660 those derived from face-specific dissolution exhibit a greater 661 standard variation around the mean value of the curves. This 662 
663 observation stems from the fact that stochastic variations in the 664 instantaneous dissolution rate of each single face are cumulated, 665 increasing the overall standard variation artificially. Interestingly, 666 when one looks at the variation of the dissolution rate as a 667 function of the number of elapsed iterations (Figure 7a), the 668 mean value of the results derived from the face-specific approach 669 is slightly lower than the one derived from the simulations 670 performed with rectangular parallelepipeds. This slight differ671 ence may be explained by the contribution of corners and edges 672 to the dissolution rate/flux. However, contrary to other 673 minerals, the dissolution of these surface sites seems to have a 674 negligible impact. A scheme exhibiting the difference between 675 enstatite and a Kossel crystal ${ }^{9,19,36,37,59-61}$ dissolution, for which 676 the contribution of edges and corners was shown in previous 677 studies to be significant, is depicted in Figures 9 and 10 to
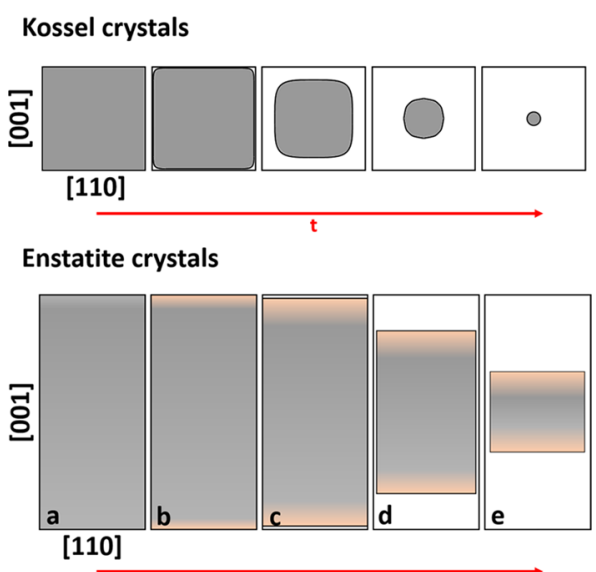

Figure 10. Scheme of the effect of dissolution through time on Kossel and enstatite crystals. Kossel: the high probability of departure of edge and corner sites leads to a rounding of the corresponding locations. This modifies significantly the crystal shape during the dissolution, which evolves from a cubic to a spherical shape. Black squares represent the crystal shape at $t=0$. The gray area represents a section of the crystal. Enstatite: At the beginning of the dissolution, $\mathrm{Mg}$ atoms are preferentially dissolved due to their particularly incomplete first coordination sphere, leading to the formation of a Si-enriched layer (orange area) on the (001) face $(a-c)$. The Si-enriched layer reaches its constant depth $(b, c)$ and the dissolution becomes stoichiometric. Both $\mathrm{Si}$ and $\mathrm{Mg}$ atoms are dissolved preferentially on the (001) face, but a few are dissolved on the (100) and (010) faces $(c-e)$. This dissolution behavior makes the rounding of the crystals unlikely.

678 explain this counterintuitive result. These schemes are based on 679 the periodic bond chain theory, ${ }^{17}$ which governs silicate 680 dissolution. In a Kossel crystal, the volume is composed of a 681 unique component ("atom"), leading to the existence of a single 682 type of bond. By nature, a Kossel crystal will have specific surface 683 sites (adatoms, steps, and kinks) with a high probability of 684 departure, leading to the rounding of the simulated crystals over 685 time. In the case of enstatite, the anisotropic nature of pyroxenes 686 makes this morphological evolution simpler. As opposed to, e.g., 687 tectosilicates, which have a three-dimensional framework of 688 silica tetrahedrons, inosilicates are composed of silica chains 689 oriented following a specific direction (parallel to the $c$-axis in 690 enstatite). In enstatite, $\mathrm{Mg}$ and $\mathrm{Si}$ atoms are also organized in 691 planes parallel to the (100) face. This particular organization 692 explains the anisotropy of dissolution of enstatite, as discussed in 693 Bouissonnié et al., ${ }^{16}$ and likely explains why macro steps and 694 corners do not play an essential role in the evolution of the dissolution rate with time. Indeed, as shown in Figure 9, most of 695 enstatite dissolution flux is supported by (001) faces. This is due 696 to the fact that the release of $\mathrm{Si}$ from $(h k 0)$ faces requires the 697 simultaneous cleavage of two $\mathrm{Si}-\mathrm{O}-\mathrm{Si}$ bonds, while the release 698 of $\mathrm{Si}$ from (001) faces requires the cleavage of one $\mathrm{Si}-\mathrm{O}-\mathrm{Si} 699$ bond only.

This specific anisotropic structure also explains why the 701 model depicted in Section 4.2 successfully matches the outputs 702 of the simulations run with enstatite parallelepipeds, indirectly 703 suggesting that no rounding of the crystals occurs with time. The 704 greater probability to release $\mathrm{Mg}$ atoms to the solution results in 705 the formation of a $\mathrm{Mg}$-depleted zone at the mineral surfaces 706 during the first iterations (Figure 4), where the mineral- 707 solution interface is only composed of chains of $\mathrm{Si}$ atoms (Figure 708 9). This process is more pronounced at the surface of the (001) 709 faces, where $\mathrm{Mg}$ atoms have the greater departure probabilities. 710 This is fully consistent with the experimentally observed thicker 711 amorphous silica layers on (001) faces. If the (001) faces exhibit 712 a Mg-depleted mineral-solution interface, then it means that it 713 is composed essentially on silica chains, not connected between 714 them (Figure 9). These silica chains will be present throughout 715 the entire surface of the (001) face but, as their topmost Si atoms 716 all exhibit the same departure probability, a rounding of the 717 edges and kinks is unlikely to happen.

718

In summary, the dissolution of a Kossel crystal can be 719 described as follows: (i) Initial fast release of atoms from the 720 kinks and edges of the minerals; (ii) Through time, the Kossel 721 crystal habit evolves from a cubic to an almost spheroidal shape. 722 Conversely, the dissolution behavior of enstatite and more 723 generally, of pyroxenes, can be summarized as follows: (i) Rapid 724 depletion of the topmost $\mathrm{Mg}$ atoms from the (001) faces; (ii) 725 stabilization of the thickness of the corresponding silica layer; 726 and (iii) propagation of the dissolution front mainly from the 727 (001) faces. These mechanistic explanations are summarized in 728 Figures 9 and 10. Also, as mentioned in Section 2.4, the model is 729 not able to reproduce the amorphous silica layer. Then, the 730 interface mainly composed of $\mathrm{Si}$ atoms remains "crystalline" 731 with only disconnected silica chains. This may present a 732 limitation to the mechanisms developed above as, in natural 733 environment, a thicker amorphous silica layer may impact the 734 crystal shape evolution. Extending this discussion to other 735 minerals requires a specific treatment of other classes of 736 minerals, which is out of the scope of this study. However, it 737 is likely that many minerals, which highlight an anisotropy 738 similar to pyroxenes could observe a similar dissolution 739 mechanism. One could argue that many minerals are more 740 anisotropic than enstatite because of its orthorhombic Bravais 741 lattice, which has a high symmetry level. However, the notion of 742 anisotropy here refers to the organization of the Si tetrahedrons. 743 In this regard, orthorhombic inosilicates are less isotropic than, 744 e.g., triclinic tectosilicates, which have a three-dimensional 745 framework of silica tetrahedrons, even though the symmetry 746 level of the orthorhombic system is higher than that of the 747 triclinic system.

Finally, the main discrepancy between model's outputs and 749 theoretical results is observed at the end of the simulations. 750 While the dissolution rates calculated using the simulations run 751 with rectangular parallelepipeds reach 0 at the end of the 752 reaction, indicating that all of the material is consumed, it is not 753 the case for the rates calculated based on face-specific 754 dissolution rates and using eqs $10 \mathrm{a}$ and $10 \mathrm{~b}$. This observation 755 is an artifact resulting from the mathematical construction of the 756 model. While faces (100), (010), and (001) are considered, the 757 
758 dissolution is mainly controlled by the sole (001) face. Equation 759 10b implies that all faces dissolve independently so that when 760 the length of the parallelepiped following the $z$-axis reaches 0 , it 761 is not the case for the two other axes. Therefore, following eq $76210 \mathrm{~b}$, a plan of enstatite contained in the two-dimensional (2D) 763 (xOy) plan still exists and continues to fuel the dissolution. 764 Conversely, in the real world (and in the simulations run with 765 rectangular parallelepipeds), the dissolution stops when the 766 crystal is completely dissolved.

767 4.4. Comparing Modeled Dissolution Fluxes and 768 Experimental Results. 4.4.1. Comparison Based on Dis769 solution Experiments Conducted with Powdered vs Single770 Face Enstatite. In the previous section, it has been shown that it 771 is possible to reproduce the grain dissolution behavior with a 772 simple mathematical model considering the dissolution fluxes of 773 the faces in contact with the fluid. However, this good agreement 774 was obtained using simulation results only. While, theoretically, 775 the model used in the present study is also able to reproduce 776 experimental data, ${ }^{16}$ the corresponding validation has been 777 previously based on a comparison with measured face-specific 778 dissolution fluxes only, and not with results from powder 779 experiments. This missing comparison is therefore attempted 780 hereafter. As a first step, we use below the additivity property of 781 single-face dissolution fluxes illustrated in Section 4.3 to 782 compare the results of dissolution experiments previously 783 conducted with single faces with those conducted with 784 powdered enstatite.

785 In their study, Oelkers and Schott ${ }^{11}$ have determined the 786 dissolution flux of enstatite powder over a wide range of $\mathrm{pH}$ and 787 temperature. Using the reaction order with respect to $\left[\mathrm{H}^{+}\right]$and 788 the activation energy derived from their study, the dissolution 789 flux of enstatite powder at $90{ }^{\circ} \mathrm{C}$ and $\mathrm{pH} 0$ (the chemical 790 conditions simulated in this study) should be around $2.35 \times$ $79110^{-8} \mathrm{~mol} /\left(\mathrm{m}^{2} \mathrm{~s}\right)$. In our previous study, the different dissolution 792 fluxes of the four main faces naturally exposed in enstatite have 793 been determined to yield $5.22 \times 10^{-9}, 5.92 \times 10^{-9}, 1.7 \times 10^{-8}$, 794 and $1.44 \times 10^{-7} \mathrm{~mol} /\left(\mathrm{m}^{2} \mathrm{~s}\right)$ for the faces (100), (010), (210), 795 and (001) respectively ${ }^{16}$ (note that the results of Bouissonnie et 796 al. $^{16}$ were corrected by a 2 -fold factor, as they considered $797 \mathrm{Mg}_{2} \mathrm{Si}_{2} \mathrm{O}_{6}$ as the chemical formula for enstatite, whereas Oelkers 798 and $\left.\mathrm{Schott}_{\text {used }} \mathrm{MgSiO}_{3}\right)$. The main cleavage plan of enstatite is $799\{210\}^{62}$ and is likely to be the most abundant when enstatite is 800 crushed prior to run powder dissolution experiments. If one 801 assumes that, in enstatite powders, mostly (210) and (001) faces 802 are present, then based on the results of the previous section, the 803 dissolution flux of the powder can be calculated following:

804

$$
r=\frac{4 * S_{(210)} * r^{(210)}+2 * S_{(001)} * r^{(001)}}{S_{0}}
$$

805 where $S_{(h k l)}$ is the surface area of the $(h k l)$ face $\left(\mathrm{m}^{2}\right), r^{(h k l)}$ is the 806 dissolution flux $\left(\mathrm{mol} /\left(\mathrm{m}^{2} \mathrm{~s}\right)\right)$ of the $(h k l)$ face, and $S_{0}$ is the 807 initial surface area $\left(\mathrm{m}^{2}\right)$. Depending on the size of the grains 808 used in this calculation $\left(10 \times 10 \times 100\right.$ or $20 \times 20 \times 100 \mu \mathrm{m}^{3}$, 809 consistent with the grain size range reported in the Oelkers and 810 Schott study), the dissolution flux is estimated to be $2.85 \times 10^{-8}$ 811 and $2.31 \times 10^{-8} \mathrm{~mol} /\left(\mathrm{m}^{2} \mathrm{~s}\right)$ for $20 \times 20 \times 100$ and $10 \times 10 \times$ $812100 \mu \mathrm{m}^{3}$ crystals, respectively. These values are in excellent 813 agreement with the dissolutions flux calculated based on the 814 study of Oelkers and Schott (hereafter referred to as $\left.r_{\mathrm{OS}}\right)(2.35 \times$ $\left.81510^{-8} \mathrm{~mol}\left(\mathrm{~m}^{2} \mathrm{~s}\right)\right)$. This agreement further supports that edges 816 and corners must negligibly contribute to the dissolution flux of 817 enstatite grains, consistent with the previous section.
4.4.2. Testing Different Methods to Upscale Dissolution 818 Fluxes from Face-Specific Simulations to Powder Dissolution 819 Experiments. The ability of the model to reproduce dissolution 820 fluxes derived from powder experiments with dissolution fluxes 821 derived from face-specific simulations and experiments has been 822 shown in Sections 4.3 and 4.4.1, respectively. However, 823 simulating directly the dissolution of entire crystals with 824 dimensions of typical grains used in laboratory experiments 825 remains out of reach with current numerical methods. Indeed, 826 our computational capabilities allow us to simulate the 827 dissolution of crystals up to $0.1 \times 0.1 \times 1 \mu \mathrm{m}^{3}$, whereas the 828 typical enstatite grain size for powder dissolution experi- 829 ments ${ }^{11,50}$ is on the order of $10 \times 10 \times 100 \mu \mathrm{m}^{3}$.

830

To circumvent this problem, a solution is to consider the good 831 agreement between the results of the simulations run with 832 rectangular parallelepipeds and the results calculated using face- 833 specific dissolution (eq 10a). As the surface retreat does not 834 depend on the considered surface area, each of the three main 835 phases of the dissolution of a given face (i.e., initial transient 836 regime, steady-state regime, i.e., linear increase of the surface 837 retreat with iterations, and terminal regime) extends over a 838 similar number of iterations, whatever the surface area 839 considered. We used this property to simulate the dissolution 840 of crystals with dimensions approaching those of grains used in 841 classical powder dissolution experiments (see Figure 11). This $842 \mathrm{fl1}$ process is repeated for all faces to simulate the dissolution of an 843 entire parallelepiped. The results of the simulations conducted 844 with this large volume are shown in Figures 5 b and 6 b (black 845 curves). This process allows studying the evolution of the 846 dissolution behavior over a wide range of volumes and also to 847 understand how such systems evolve. Ultimately, the simulation 848 of such large volumes allows comparing modeled and 849 experimental data.

The first important highlight is that no real steady state is 851 reached for dissolution rate/flux (Figures $5 \mathrm{~b}$ and $6 \mathrm{~b}$ ). Indeed, 852 the dissolution rate and flux steadily increase over the course of 853 the simulation. This may be due to the evolution of the surface 854 area that is not correctly captured, as the calculation does not 855 consider its intrinsic variability over the entire surface (intrinsic 856 reactivity and etch pits formation for example). However, the 857 increase is slow and not significant (below $14 \mathrm{nmol} / \mathrm{s}$, which 858 would remain out of reach of conventional techniques used to 859 measure dissolution fluxes in the laboratory), and this regime 860 can therefore be approximated to a steady state. This pseudo- 861 steady state corresponds to a mean dissolution flux of 862 approximately $1.8 \times 10^{16} \mathrm{Si}$ atoms $/\left(\mathrm{m}^{2}\right.$ iteration $)$ which yields 863 $2.62 \times 10^{-8} \mathrm{~mol} /\left(\mathrm{m}^{2} \mathrm{~s}\right)$, if one applies the time/iteration 864 relationship calculated by Bouissonnie et al. ${ }^{16}\left(r\left(\mathrm{~mol} /\left(\mathrm{m}^{2} \mathrm{~s}\right)\right)=865\right.$ $0.876 \times r\left(\mathrm{~mol} /\left(\mathrm{m}^{2}\right.\right.$ iteration $\left.\left.)\right)\right)$. This value is in very good 866 agreement with that determined by Oelkers and Schott $(\sim 1.11867$ $\left.r_{\mathrm{OS}}\right)$.

Three additional upscaling methods are tested and compared 869 with $r_{\text {OS. }}$.

The first method consists of considering the dissolution fluxes 871 determined with single-face dissolution experiments: ${ }^{16}$ (a) with 872 faces (100), (010), and (001) and (b) with faces (210) and 873 (001) 

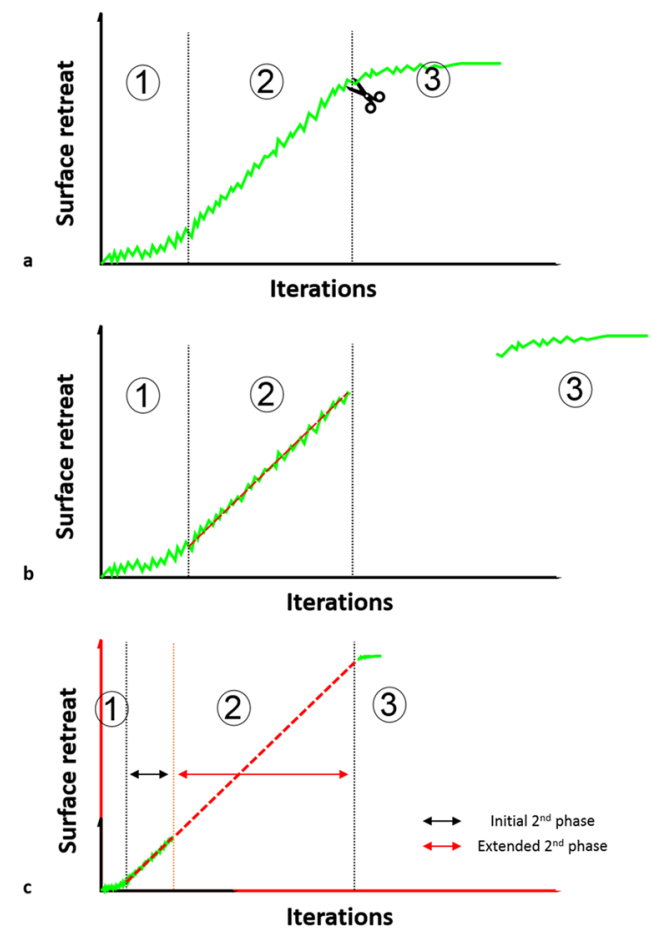

Figure 11. Scheme of the method followed to get the dissolution flux of enstatite rectangular parallelepipeds with a size comparable to those used in Oelkers and Schott. ${ }^{11}$ (a) Surface retreat simulated as a function of the iterations is used for each considered face (e.g., (100), (010), and (001)). It is divided into three different phases: (1) the transient regime, (2) the steady-state regime, and (3) the terminal regime, corresponding to the consumption of the remaining atoms in the materials. A cut is operated between the second and third phases. (b) A linear regression (dashed red line) is applied, based on the results of the steady-state phase starting from the transition between the first and second phases and ended between the second and third phases. (c) Linear regression is used to increase the size of the parallelepiped to reach the size used by Oelkers and Schott. The third phase is then added at the end of the extended second phase.

$$
\begin{aligned}
& r=\frac{16^{*} \Delta V(\Delta t)}{a^{*} b^{*} c^{*} \Delta t^{*} S_{0} * N_{\mathrm{A}}} \\
& \begin{aligned}
\Delta V(\Delta t)= & V_{t}-\left(x_{t}-2 \Delta h_{\Delta t}^{(100) !(210)}\right)\left(y_{t}-2 \Delta h_{\Delta t}^{(010) \mid(210)}\right) \\
& \left(z_{t}-2 \Delta h_{\Delta t}^{(001)}\right)
\end{aligned}
\end{aligned}
$$

875 876 where $r$ is the dissolution flux $\left(\mathrm{mol} /\left(\mathrm{m}^{2} \mathrm{~s}\right)\right), \Delta t$ is the time 877 interval considered for the calculation $(\mathrm{s}), S_{0}$ is the initial surface $878\left(\mathrm{~m}^{2}\right), N_{\mathrm{A}}$ is the Avogadro number $\left(\mathrm{mol}^{-1}\right), \Delta V(\Delta t)$ is the 879 difference of volumes over the time interval $\Delta t\left(\mathrm{~m}^{3}\right)$, and $\Delta h_{\Delta t}^{(h k l)}$ 880 is the surface retreat of the $(h k l)$ face over the time interval $\Delta t$. 881 The second method uses the surrogate relation between the 882 dissolution flux and the probabilities (i.e., activation energies) 883 determined in Bouissonnié et al. ${ }^{41}$

$$
\frac{\Delta h_{(h k l)}}{\Delta t} 0.876\left[\begin{array}{l}
k P_{\mathrm{Mg}-\mathrm{O}-\mathrm{Mg}}^{\alpha} P_{\mathrm{Mg}-\mathrm{O}-\mathrm{Si}}^{\beta} P_{\mathrm{Si}-\mathrm{O}-\mathrm{Si}}^{\gamma}+ \\
k_{\text {dis }} P_{\mathrm{Mg}-\mathrm{O}-\mathrm{Mg}}^{\alpha_{\text {dis }}} P_{\mathrm{Mg}-\mathrm{O}-\mathrm{Si}}^{\beta_{\text {dis }}} P_{\mathrm{Si}-\mathrm{O}-\mathrm{Si}}^{\gamma_{\text {dis }}}\left(1-\mathrm{e}^{-\rho_{\mathrm{d}} / \omega}\right)
\end{array}\right]
$$

885 with $k, k_{\mathrm{dis}}, \alpha, \beta, \gamma, \alpha_{\mathrm{dis}}, \beta_{\mathrm{dis}}, \gamma_{\mathrm{dis}}$, and $\omega$ being empirical 886 parameters and $\rho_{\mathrm{d}}$ the dislocation density. The left-hand side of 887 the sum referred to the "bulk" dissolution flux, while the right888 hand side referred to the contribution etch pits at dislocation outcrops. The values of these parameters were determined in 889 Bouissonnie et al. ${ }^{41}$ and are listed in Table 1. $890 \mathrm{t} 1$

Table 1. Numerical Values of the Parameters in Equation 12 and Taken from Bouissonnié et al. ${ }^{41 a}$

\begin{tabular}{llll}
\multicolumn{1}{c}{ face } & \multicolumn{1}{c}{$(100)$} & \multicolumn{1}{c}{$(010)$} & $(001)$ \\
$k(\AA /$ it $)$ & 8.87 & 7.8 & 4.72 \\
$\alpha$ & 2.46 & 2.22 & 6.36 \\
$\beta$ & 4.62 & 4.65 & 4.19 \\
$\gamma$ & 0.94 & 0.75 & 0.14 \\
$k_{\text {dis }}(\AA /$ it $)$ & 44.7 & $44.7^{*}$ & \\
$\alpha_{\text {dis }}$ & 2.09 & $2.09^{*}$ & \\
$\beta_{\text {dis }}$ & 4.09 & $4.09^{*}$ & \\
$\gamma_{\text {dis }}$ & 0.67 & $0.67^{*}$ & \\
$\omega$ & $5.51 \times 10^{10}$ & $5.51 \times 10^{10 *}$ & \\
$\rho_{\text {d }}\left(/ \mathrm{cm}^{2}\right)$ & $4.9 \times 10^{8}$ & $9.8 \times 10^{6}$ & 0
\end{tabular}

${ }^{a} \alpha, \beta$, and $\gamma$ represent fitting parameters for bulk dissolution rate (without the presence of dislocation). $\alpha_{\text {dis }}, \beta_{\text {dis, }}$ and $\gamma_{\text {dis }}$ represent fitting parameters for dissolution rate impacted by the presence of dislocations. The parameters $k$ and $k_{\text {dis }}$ represent the dissolution constant for bulk dissolution rate and dissolution rate impacted by the dislocation, respectively. $\omega$ is a fitting parameter, and $\rho_{\mathrm{d}}$ is the dislocation density measured in Bouissonnié et al. ${ }^{16}(*)$ Parameters corresponding to the presence of dislocation on the (010) face were not studied. For this study, it has been assumed that they were equal to those of the (100) face.

The last method considers the modeled face-specific 891 dissolution fluxes given in Bouissonnié et al. ${ }^{16} 892$

The three methods were applied on $20 \times 20 \times 100$ and $10 \times 893$ $10 \times 100 \mu \mathrm{m}^{3}$ rectangular parallelepipeds (considered as a 894 model shape and size for the grains used in Oelkers and 895 Schott $\left.{ }^{1,50}\right)$, and the results are summarized in Table 2. Overall, 896 t2 all methods exhibit a satisfactory agreement with the results 897 obtained experimentally, with discrepancies never exceeding 898 $50 \%$. Of note, a better agreement is obtained when the $\{210\} 899$ face is considered. This observation may confirm that enstatite 900 grains were mainly shaped with $\{210\}$ face in the powder used 901

Table 2. Numerical Values of the Steady-State Dissolution

\begin{tabular}{|c|c|c|c|}
\hline method & crystal size $\left(\mathrm{m}^{3}\right)$ & $\begin{array}{c}\text { dissolution flux } \\
\left(r=\mathrm{mol} /\left(\mathrm{m}^{2} \mathrm{~s}\right)\right)\left(\times 10^{-8}\right)\end{array}$ & $r / r_{\mathrm{OS}}$ \\
\hline \multirow{2}{*}{$\begin{array}{l}\text { surface retreat } \\
\text { of }(100) \text {, } \\
(010), \text { and } \\
(001)^{16}\end{array}$} & $20 \times 20 \times 100 \mu \mathrm{m}^{3}$ & 1.78 & 0.76 \\
\hline & $10 \times 10 \times 100 \mu \mathrm{m}^{3}$ & 1.18 & 0.50 \\
\hline \multirow{2}{*}{$\begin{array}{l}\text { surface retreat } \\
\text { of }(210) \text { and } \\
(001)^{16}\end{array}$} & $20 \times 20 \times 100 \mu \mathrm{m}^{3}$ & 2.75 & 1.17 \\
\hline & $10 \times 10 \times 100 \mu \mathrm{m}^{3}$ & 2.17 & 0.92 \\
\hline \multirow{2}{*}{$\begin{array}{l}\text { surrogate } \\
\text { model }^{41}\end{array}$} & $20 \times 20 \times 100 \mu \mathrm{m}^{3}$ & 2.22 & 0.94 \\
\hline & $10 \times 10 \times 100 \mu \mathrm{m}^{3}$ & 1.62 & 0.69 \\
\hline this study & $20 \times 20 \times 100 \mu \mathrm{m}^{3}$ & 2.62 & 1.11 \\
\hline \multirow{2}{*}{$\begin{array}{l}\text { single-face- } \\
\text { modeled } \\
\text { results }\end{array}$} & $20 \times 20 \times 100 \mu \mathrm{m}^{3}$ & 1.88 & 0.8 \\
\hline & $10 \times 10 \times 100 \mu \mathrm{m}^{3}$ & 1.35 & 0.57 \\
\hline
\end{tabular}
Flux of an Enstatite Grain Considering the Simple Relation between Face-Specific Dissolution Flux and Powder Dissolution Flux Following Several Methods ${ }^{a}$

${ }^{a_{T}}$ The agreement (evaluated by the $r / r_{\mathrm{OS}}$ ratio) between powder dissolution experiments of Oelkers and $S$ chott $^{11}$ and results obtained from face-specific dissolution experiments and modeling taken from Bouissonnié et al. ${ }^{16,41}$ are reported in the last column. Crystal size has been chosen according to that reported in Oelkers and Schott, and an aspect ratio consistent with Dana. ${ }^{50}$ 
902 by Oelkers and Schott, which is consistent with the fact that $903\{210\}$ represents the main cleavage plan of enstatite.

\section{4.5. Relevance for Mineral Dissolution Studies and} 905 Limitations. Both experimental results obtained with face906 specific dissolution measurements and those obtained with the 907 stochastic dissolution model run with rectangular parallelepi908 peds succeed to reproduce the dissolution rates/fluxes measured 909 during powder dissolution experiment. Here, we showed that 910 face-specific and powder dissolution rates can be linked using a 911 simple relation. However, this may be only true in the case of 912 very anisotropic minerals such as enstatite (and pyroxenes) 913 because edges and corners contribute negligibly to the 914 dissolution flux. This conclusion does not hold for calcite, for 915 example, as Noiriel et al. ${ }^{25}$ showed that corners dissolve faster 916 than (104) cleavage plans. In our opinion, our results would 917 justify investigating the dissolution of other minerals according 918 to the methods reported here to determine the crystallographic 919 structures for which dissolution obeys relations similar to those 920 evidenced for enstatite.

921 The results presented here may also be useful to model silicate 922 weathering in natural environments. Subsurface environments 923 present a wide diversity of textures, from porous to fractured 924 media. Although fractured media should involve a preferential 925 water/solid interaction of a limited number of mineral cleavage 926 planes, porous media can exhibit a greater variety of mineral 927 faces in contact with water. Actually, as a first approximation, 928 micrometer-wide enstatite grains may be simplified as 929 rectangular parallelepipeds made of (210) and (001) faces 930 only, for which the length of the crystal in the z-direction is 5-10 931 times greater than in the other directions leading to consider the 932 dissolution rate given by eq 12 . This result may still hold true in 933 less acidic environment as long as the fluid is far from 934 equilibrium with respect to $\mathrm{SiO}_{2(\mathrm{am})}{ }^{48}$ The fact that face935 specific and powder dissolution studies can be linked through a 936 simple relation for anisotropic minerals may imply that face937 specific dissolution studies offer a greater interest than those 938 conducted with powders for minerals presenting an anisotropy 939 similar to the one of enstatite. In addition, our study shows the 940 prevalence of fast dissolving faces over the others, suggesting 941 that face-specific dissolution studies should target in priority 942 such faces. Overall, the agreement between the outputs of the 943 model and the theoretical results detailed in Section 4.2 shows 944 how important it is to consider the evolution of the reactive 945 surface area in geochemical/reactive-transport studies/models. 946 The evolution of the aspect ratio was shown to be important in 947 both cases when the reaction progress reaches approximately $94880 \%$. Indeed, at this step, the aspect ratio has evolved enough so 949 that the reaction flux is characterized by a sharp increase. This 950 may be of great interest to model chemical weathering in the 951 regolith, where primary materials are altered into secondary 952 minerals and may be the main contributors of dissolved 953 elements in springs and rivers.

954 Interestingly, the simulated instantaneous release rates of $\mathrm{Mg}$ 955 and $\mathrm{Si}$ atoms as a function of time (Figure 4) exhibit a specific 956 shape that corresponds in every way to the calorimetry curves 957 depicting the progress of cement hydration (cf. Figures $2-4$ in 958 Luc et al. $^{63}$ ), for which the rate-limiting step is supposed to be 959 the dissolution of silicate minerals such as alite. It is noteworthy 960 that such a shape has puzzled the materials sciences community 961 for a couple of decades, since it reveals a strong nonlinearity of 962 the dissolution rate with time, which is at odds with existing 963 models of mineral reactivity. ${ }^{64}$ While previous attempts did not 964 succeed to fully account for such observations, ${ }^{65,66}$ the present study suggests that the anisotropic dissolution of silicates may 965 indeed result in a general dissolution pattern consistent with 966 previous measurements of cement hydration, representing 967 relevant new avenues to be investigated in greater details. 968

Finally, among the main limitations of our study, the 969 development of amorphous silica-rich surface layers through 970 silica redeposition or surface network reorganization was not 971 considered, as the impact of such layers is suspected to be 972 nonsignificant in the experimental conditions investi- 973 gated $^{3,47,67,68}$ by Bouissonnié et al. ${ }^{16}$ (i.e., very acidic $\mathrm{pH}$ and 974 low concentrations of aqueous silica). The implementation in 975 the stochastic dissolution code of backward reactions of Si 976 attachment, as described in, e.g., Zhang and Lüttge ${ }^{69}$ or the 977 consideration of $\mathrm{M}-\mathrm{O}$ hydrolysis instead of $\mathrm{M}-\mathrm{O}-\mathrm{M} 978$ hydrolysis would be required to ultimately get closer to 979 conditions operating in natural settings.

980

\section{CONCLUSIONS}

In this work, we simulated the dissolution of enstatite grains with 981 a stochastic dissolution model developed at the atomic scale. By 982 varying the size of the simulated grains, we showed that the main 983 factor impacting the temporal evolution of the dissolution rate is 984 the aspect ratio. A similar evolution of the dissolution rate 985 through time is observed for grains with the same aspect ratio. 986 Furthermore, different parameters such as the maximum 987 dissolution rate, initial volume, dissolution at a given volume, 988 and reaction progress were linked together through empirical 989 functions.

One of the main outcomes of this study was provided by 991 comparing the outputs of the stochastic grain dissolution with a 992 theoretical dissolution model based on the sole contribution of 993 face-specific dissolution, neglecting the contribution of edges 994 and corners. The very good agreement between the two 995 methods highlights the modest effects of edges and corners 996 during enstatite dissolution, and probably, during the dis- 997 solution of other very anisotropic minerals as well (i.e., minerals 998 where the stronger atomic bonds are aligned in a specific 999 direction).

1000

The comparison between modeled and experimental results 1001 obtained by Oelkers and Schott ${ }^{11}$ on powder dissolution also 1002 revealed an excellent agreement. This led to the conclusion that 1003 powder dissolution results from the specific contribution of each 1004 face in a very simple way, making it possible to link the different 1005 experimental works performed in a laboratory. 1006

Finally, this study shows the importance of fast dissolving 1007 faces. Indeed, almost the entire dissolution rate relies on the 1008 dissolution of the face (001). However, if the dissolution rates of 1009 the fastest dissolving faces are prominent, the overall dissolution 1010 rate is strongly correlated to the surface area of the other slower 1011 faces. This result supports the idea that reactive surface is one of 1012 the most important parameters in water/mineral interactions 1013 studies and that one must be aware, particularly in reactive- 1014 transport studies, of what is the reactive surface and how it 1015 should be taken into account.

AUTHOR INFORMATION

Arnaud Bouissonnié - Laboratoire d'Hydrologie et de 1019 Géochimie de Strasbourg, Université de Strasbourg-CNRS/ 1020 ENGEES-EOST, 67084 Strasbourg, France; (1) orcid.org/ 1021 0000-0003-4590-5631; Phone: +33 (0)3 688505 47; 1022 Email: arnaud.bouissonnie@etu.unistra.fr; Fax: +33(0)3 1023 68850402 


\section{Authors}

1026 Damien Daval - Laboratoire d'Hydrologie et de Géochimie de 1027 Strasbourg, Université de Strasbourg-CNRS/ENGEES-

1028 EOST, 67084 Strasbourg, France; (1) orcid.org/0000-0002$1029 \quad 4395-6681$

1030 Philippe Ackerer - Laboratoire d'Hydrologie et de Géochimie 1031 de Strasbourg, Université de Strasbourg-CNRS/

1032 ENGEES-EOST, 67084 Strasbourg, France

1033 Complete contact information is available at:

1034 https://pubs.acs.org/10.1021/acs.jpcc.0c11416

\section{Notes}

1036 The authors declare no competing financial interest.

\section{ACKNOWLEDGMENTS}

1038 A.B. thanks the University of Strasbourg and CNRS for having 1039 funded his Ph.D. grant. The authors thank two anonymous 1040 reviewers for their helpful comments.

\section{$1041 \square$ REFERENCES}

1042 (1) White, A. F.; Brantley, S. L. The Effect of Time on the Weathering 1043 of Silicate Minerals: Why Do Weathering Rates Differ in the Laboratory 1044 and Field? Chem. Geol. 2003, 202, 479-506.

1045 (2) Daval, D.; Martinez, I.; Corvisier, J.; Findling, N.; Goffé, B.; Guyot, 1046 F. Carbonation of Ca-Bearing Silicates, the Case of Wollastonite: 1047 Experimental Investigations and Kinetic Modeling. Chem. Geol. 2009, 1048 265, 63-78.

1049 (3) Daval, D.; Hellmann, R.; Saldi, G. D.; Wirth, R.; Knauss, K. G. 1050 Linking Nm-Scale Measurements of the Anisotropy of Silicate Surface 1051 Reactivity to Macroscopic Dissolution Rate Laws: New Insights Based 1052 on Diopside. Geochim. Cosmochim. Acta 2013, 107, 121-134.

1053 (4) Smith, M. E.; Knauss, K. G.; Higgins, S. R. Effects of Crystal 1054 Orientation on the Dissolution of Calcite by Chemical and Microscopic 1055 Analysis. Chem. Geol. 2013, 360-361, 10-21.

1056 (5) Pollet-Villard, M.; Daval, D.; Fritz, B.; Knauss, K. G.; Schäfer, G.; 1057 Ackerer, P. Influence of Etch Pit Development on the Surface Area and 1058 Dissolution Kinetics of the Orthoclase (001) Surface. Chem. Geol. 1059 2016, 447, 79-92.

1060 (6) Saldi, G. D.; Voltolini, M.; Knauss, K. G. Effects of Surface 1061 Orientation, Fluid Chemistry and Mechanical Polishing on the 1062 Variability of Dolomite Dissolution Rates. Geochim. Cosmochim. Acta 1063 2017, 206, 94-111.

1064 (7) Godinho, J. R. A.; Piazolo, S.; Evins, L. Z. Effect of Surface 1065 Orientation on Dissolution Rates and Topography of CaF2. Geochim. 1066 Cosmochim. Acta 2012, 86, 392-403.

1067 (8) Ruiz-Agudo, E.; King, H. E.; Patiño-López, L. D.; Putnis, C. V.; 1068 Geisler, T.; Rodriguez-Navarro, C.; Putnis, A. Control of Silicate 1069 Weathering by Interface-Coupled Dissolution-Precipitation Processes 1070 at the Mineral-Solution Interface. Geology 2016, 44, 567-570.

1071 (9) Trindade Pedrosa, E.; Kurganskaya, I.; Fischer, C.; Luttge, A. A 1072 Statistical Approach for Analysis of Dissolution Rates Including Surface 1073 Morphology. Minerals 2019, 9, No. 458.

1074 (10) Oelkers, E. H.; Schott, J.; Devidal, J.-L. The Effect of Aluminum, $1075 \mathrm{PH}$, and Chemical Affinity on the Rates of Aluminosilicate Dissolution 1076 Reactions. Geochim. Cosmochim. Acta 1994, 58, 2011-2024.

1077 (11) Oelkers, E. H.; Schott, J. An Experimental Study of Enstatite 1078 Dissolution Rates as a Function of $\mathrm{PH}$, Temperature, and Aqueous $\mathrm{Mg}$ 1079 and Si Concentration, and the Mechanism of Pyroxene/Pyroxenoid 1080 Dissolution. Geochim. Cosmochim. Acta 2001, 65, 1219-1231.

1081 (12) Salehikhoo, F.; Li, L.; Brantley, S. L. Magnesite Dissolution Rates 1082 at Different Spatial Scales: The Role of Mineral Spatial Distribution and 1083 Flow Velocity. Geochim. Cosmochim. Acta 2013, 108, 91-106.

1084 (13) Kurganskaya, I.; Luttge, A. A Comprehensive Stochastic Model 1085 of Phyllosilicate Dissolution: Structure and Kinematics of Etch Pits 1086 Formed on Muscovite Basal Face. Geochim. Cosmochim. Acta 2013, 120, $1087545-560$.
(14) Perez, A.; Daval, D.; Fournier, M.; Vital, M.; Delaye, J.-M.; Gin, S. 1088 Comparing the Reactivity of Glasses with Their Crystalline 1089 Equivalents: The Case Study of Plagioclase Feldspar. Geochim. 1090 Cosmochim. Acta 2019, 254, 122-141.

1091

(15) Pollet-Villard, M.; Daval, D.; Ackerer, P.; Saldi, G. D.; Wild, B.; 1092 Knauss, K. G.; Fritz, B. Does Crystallographic Anisotropy Prevent the 1093 Conventional Treatment of Aqueous Mineral Reactivity? A Case Study 1094 Based on K-Feldspar Dissolution Kinetics. Geochim. Cosmochim. Acta 1095 2016, 190, 294-308.

1096

(16) Bouissonnié, A.; Daval, D.; Guyot, F.; Ackerer, P. The 1097 Dissolution Anisotropy of Pyroxenes: Experimental Validation of a 1098 Stochastic Dissolution Model Based on Enstatite Dissolution. J. Phys. 1099 Chem. C 2020, 124, 3122-3140.

1100

(17) Hartman, P. On the relations between structure and morphology 1101 of crystals. I. Acta Cryst. 1955, 8, 49-52.

1102

(18) Arvidson, R. S.; Ertan, I. E.; Amonette, J. E.; Luttge, A. Variation 1103 in Calcite Dissolution Rates. Geochim. Cosmochim. Acta 2003, 67, 1104 1623-1634.

1105

(19) Briese, L.; Arvidson, R. S.; Luttge, A. The Effect of Crystal Size 1106 Variation on the Rate of Dissolution-A Kinetic Monte Carlo Study. 1107 Geochim. Cosmochim. Acta 2017, 212, 167-175. 1108

(20) Kurganskaya, I.; Arvidson, R. S.; Fischer, C.; Luttge, A. Does the 1109 Stepwave Model Predict Mica Dissolution Kinetics? Geochim. 1110 Cosmochim. Acta 2012, 97, 120-130. 1111

(21) Lasaga, A. C.; Luttge, A. Variation of Crystal Dissolution Rate 1112 Based on a Dissolution Stepwave Model. Science 2001, 291, 2400- 1113 2404. 1114

(22) Fischer, C.; Luttge, A. Pulsating Dissolution of Crystalline 1115 Matter. Proc. Natl. Acad. Sci. U.S.A. 2018, 115, 897-902. 1116

(23) Lüttge, A.; Arvidson, R. S.; Fischer, C. A Stochastic Treatment of 1117 Crystal Dissolution Kinetics. Elements 2013, 9, 183-188. 1118

(24) Noiriel, C.; Oursin, M.; Saldi, G.; Haberthür, D. Direct 1119 Determination of Dissolution Rates at Crystal Surfaces Using 3D X- 1120 Ray Microtomography. ACS Earth Space Chem. 2019, 3, 100-108. 1121

(25) Noiriel, C.; Oursin, M.; Daval, D. Examination of Crystal 1122 Dissolution in 3D: A Way to Reconcile Dissolution Rates in the 1123 Laboratory? Geochim. Cosmochim. Acta 2020, 273, 1-25. 1124

(26) Kahl, W.-A.; Yuan, T.; Bollermann, T.; Bach, W.; Fischer, C. 1125 Crystal Surface Reactivity Analysis Using a Combined Approach of X- 1126 Ray Micro-Computed Tomography and Vertical Scanning Interfer- 1127 ometry. Am. J. Sci. 2020, 320, 27-52.

1128

(27) Luettge, A.; Bolton, E. W.; Lasaga, A. C. An Interferometric 1129 Study of the Dissolution Kinetics of Anorthite: The Role of Reactive 1130 Surface Area. Am. J. Sci. 1999, 299, No. 652.

1131

(28) Bourg, I. C.; Steefel, C. I. Molecular Dynamics Simulations of 1132 Water Structure and Diffusion in Silica Nanopores. J. Phys. Chem. C 1133 2012, 116, 11556-11564.

1134

(29) Molins, S.; Trebotich, D.; Yang, L.; Ajo-Franklin, J. B.; Ligocki, T. 1135 J.; Shen, C.; Steefel, C. I. Pore-Scale Controls on Calcite Dissolution 1136 Rates from Flow-through Laboratory and Numerical Experiments. 1137 Environ. Sci. Technol. 2014, 48, 7453-7460.

1138

(30) Steefel, C. I.; Appelo, C. A. J.; Arora, B.; Jacques, D.; Kalbacher, 1139 T.; Kolditz, O.; Lagneau, V.; Lichtner, P. C.; Mayer, K. U.; Meeussen, J. 1140 C. L.; et al. Reactive Transport Codes for Subsurface Environmental 1141 Simulation. Comput. Geosci. 2015, 19, 445-478. 1142

(31) Kurganskaya, I.; Luttge, A. Kinetic Monte Carlo Simulations of 1143 Silicate Dissolution: Model Complexity and Parametrization. J. Phys. 1144 Chem. C 2013, 117, 24894-24906.

1145

(32) Kurganskaya, I.; Luttge, A. Kinetic Monte Carlo Approach To 1146 Study Carbonate Dissolution. J. Phys. Chem. C 2016, 120, 6482-6492. 1147 (33) Rohlfs, R. D.; Fischer, C.; Kurganskaya, I.; Luttge, A. Crystal 1148 Dissolution Kinetics Studied by a Combination of Monte Carlo and 1149 Voronoi Methods. Minerals 2018, 8, No. 133.

1150

(34) Kurganskaya, I.; Rohlfs, R. D. Atomistic to Meso-Scale Modeling 1151 of Mineral Dissolution: Methods, Challenges and Prospects. Am. J. Sci. 1152 2020, 320, 1-26. 1153

(35) Zhang, L.; Lüttge, A. Al,Si Order in Albite and Its Effect on Albite 1154 Dissolution Processes: A Monte Carlo Study. Am. Mineral. 2007, 92, 1155 1316-1324. 
1157 (36) Meakin, P.; Rosso, K. M. Simple Kinetic Monte Carlo Models for 1158 Dissolution Pitting Induced by Crystal Defects. J. Chem. Phys. 2008, 1159 129, No. 204106.

1160 (37) de Assis, T. A.; Aarão Reis, F. D. A. Dissolution of Minerals with 1161 Rough Surfaces. Geochim. Cosmochim. Acta 2018, 228, 27-41.

1162 (38) Lasaga, A. C.; Blum, A. E. Surface Chemistry, Etch Pits and 1163 Mineral-Water Reactions. Geochim. Cosmochim. Acta 1986, 50, 236311642379.

1165 (39) Berner, R. A. GEOCARB II: A Revised Model of Atmospheric 1166 CO[Sub 2] over Phanerozoic Time. Am. J. Sci. 1994, 294, No. 56.

1167 (40) Berner, R. A.; Kothavala, Z. Geocarb III: A Revised Model of 1168 Atmospheric CO2 over Phanerozoic Time. Am. J. Sci. 2001, 301, 1821169204.

1170 (41) Bouissonnié, A.; Daval, D.; Ackerer, P. Dissolution Anisotropy of 1171 Pyroxenes: A Surrogate Model for Steady-State Enstatite Dissolution 1172 Resulting from Stochastic Simulations of the Hydrolysis Process. J. 1173 Phys. Chem. C 2020, 124, 13113-13126.

1174 (42) Hugh-Jones, D. A.; Angel, R. J. A Compressional Study of $1175 \mathrm{MgSiO} 3$ Orthoenstatite up to $8.5 \mathrm{GPa}$. Am. Mineral. 1994, 79, 4051176410.

1177 (43) Cailleteau, C.; Angeli, F.; Devreux, F.; Gin, S.; Jestin, J.; Jollivet, 1178 P.; Spalla, O. Insight into Silicate-Glass Corrosion Mechanisms. Nat. 1179 Mater. 2008, 7, 978-983.

1180 (44) Devreux, F.; Ledieu, A.; Barboux, P.; Minet, Y. Leaching of 1181 Borosilicate Glasses. II. Model and Monte-Carlo Simulations. J. Non1182 Cryst. Solids 2004, 343, 13-25.

1183 (45) Hellmann, R.; Cotte, S.; Cadel, E.; Malladi, S.; Karlsson, L. S.; 1184 Lozano-Perez, S.; Cabié, M.; Seyeux, A. Nanometre-Scale Evidence for 1185 Interfacial Dissolution-Reprecipitation Control of Silicate Glass 1186 Corrosion. Nat. Mater. 2015, 14, 307-311.

1187 (46) Gin, S.; Collin, M.; Jollivet, P.; Fournier, M.; Minet, Y.; Dupuy, 1188 L.; Mahadevan, T.; Kerisit, S.; Du, J. Dynamics of Self-Reorganization 1189 Explains Passivation of Silicate Glasses. Nat. Commun. 2018, 9, 1190 No. 2169.

1191 (47) Wild, B.; Daval, D.; Guyot, F.; Knauss, K. G.; Pollet-Villard, M.; 1192 Imfeld, G. PH-Dependent Control of Feldspar Dissolution Rate by 1193 Altered Surface Layers. Chem. Geol. 2016, 442, 148-159.

1194 (48) Daval, D.; Sissmann, O.; Menguy, N.; Saldi, G. D.; Guyot, F.; 1195 Martinez, I.; Corvisier, J.; Garcia, B.; Machouk, I.; Knauss, K. G.; et al. 1196 Influence of Amorphous Silica Layer Formation on the Dissolution 1197 Rate of Olivine at $90^{\circ} \mathrm{C}$ and Elevated PCO(2). Chem. Geol. 2011, 284, 1198 193-209.

1199 (49) Zhang, L.; Lüttge, A. Morphological Evolution of Dissolving 1200 Feldspar Particles with Anisotropic Surface Kinetics and Implications 1201 for Dissolution Rate Normalization and Grain Size Dependence: A 1202 Kinetic Modeling Study. Geochim. Cosmochim. Acta 2009, 73, 675712036770 .

1204 (50) Dana, E. S. The System of Mineralogy; John Wiley \& Sons, Inc.: 1205 New York, 1899.

1206 (51) Fischer, C.; Arvidson, R. S.; Lüttge, A. How Predictable Are 1207 Dissolution Rates of Crystalline Material? Geochim. Cosmochim. Acta 1208 2012, 98, 177-185.

1209 (52) Daval, D.; Calvaruso, C.; Guyot, F.; Turpault, M.-P. Time1210 Dependent Feldspar Dissolution Rates Resulting from Surface 1211 Passivation: Experimental Evidence and Geochemical Implications. 1212 Earth Planet. Sci. Lett. 2018, 498, 226-236.

1213 (53) Carrasco, I. S. S.; Aarão Reis, F. D. A. Modeling the Kinetics of 1214 Calcite Dissolution in Neutral and Alkaline Solutions. Geochim. 1215 Cosmochim. Acta 2021, 292, 271-284.

1216 (54) Fischer, C.; Kurganskaya, I.; Luttge, A. Inherited Control of 1217 Crystal Surface Reactivity. Appl. Geochem. 2018, 91, 140-148.

1218 (55) Beig, M. S.; Lüttge, A. Albite Dissolution Kinetics as a Function 1219 of Distance from Equilibrium: Implications for Natural Feldspar 1220 Weathering. Geochim. Cosmochim. Acta 2006, 70, 1402-1420.

1221 (56) Schott, J.; Brantley, S.; Crerar, D.; Guy, C.; Borcsik, M.; Willaime, 1222 C. Dissolution Kinetics of Strained Calcite. Geochim. Cosmochim. Acta 1223 1989, 53, 373-382.
(57) Xu, J.; Fan, C.; Teng, H. H. Calcite Dissolution Kinetics in View 1224 of Gibbs Free Energy, Dislocation Density, and PCO2. Chem. Geol. 1225 2012, 322-323, 11-18.

1226

(58) Teng, H. H. Controls by Saturation State on Etch Pit Formation 1227 during Calcite Dissolution. Geochim. Cosmochim. Acta 2004, 68, 253- 1228 262. 1229

(59) Lasaga, A. C. Fundamental Approaches in Describing Mineral 1230 Dissolution and Precipitation Rates. In Chemical Weathering Rates of 1231 Silicate Minerals; White, A. F.; Brantley, S. L., Eds.; Mineralogical 1232 Society of America, 1995; Vol. 31, pp 23-86.

1233

(60) Kossel, W. Zur theorie des kristallwachstums. Nachr. Ges. Wiss. 1234 Goettingen, Math.-Phys. Kl. 1927, 1927, 135-143. 1235

(61) Stranski, I. N. Zur Theorie Des Kristallwachstums. Z. Phys. Chem. 1236 1928, 136U, 259-278.

1237

(62) Skrotzki, W. Defect Structure and Deformation Mechanisms in 1238 Naturally Deformed Hornblende. Phys. Status Solidi A 1992, 131, 605- 1239 624.

1240

(63) Luc, N.; André, N.; Damien, D. Rate-Limiting Reaction of C3S 1241 Hydration-A Reply to the Discussion "A New View on the Kinetics of 1242 Tricalcium Silicate Hydration” by E. Gartner. Cem. Concr. Res. 2018, 1243 $104,118-122$. 1244

(64) Steefel, C. I.; Maher, K. Fluid-Rock Interaction: A Reactive 1245 Transport Approach. Rev. Mineral. Geochem. 2009, 70, 485-532. 1246

(65) Nicoleau, L.; Bertolim, M. A. Analytical Model for the Alite 1247 (C3S) Dissolution Topography. J. Am. Ceram. Soc. 2015, 99, 773-786. 1248

(66) Robin, V.; Wild, B.; Daval, D.; Pollet-Villard, M.; Nonat, A.; 1249 Nicoleau, L. Experimental Study and Numerical Simulation of the 1250 Dissolution Anisotropy of Tricalcium Silicate. Chem. Geol. 2018, 497, 1251 64-73.

1252

(67) Daval, D.; Bernard, S.; Rémusat, L.; Wild, B.; Guyot, F.; Micha, J. 1253 S.; Rieutord, F.; Magnin, V.; Fernandez-Martinez, A. Dynamics of 1254 Altered Surface Layer Formation on Dissolving Silicates. Geochim. 1255 Cosmochim. Acta 2017, 209, 51-69.

1256

(68) Wild, B.; Daval, D.; Micha, J.-S.; Bourg, I. C.; White, C. E.; 1257 Fernandez-Martinez, A. Physical Properties of Interfacial Layers 1258 Developed on Weathered Silicates: A Case Study Based on Labradorite 1259 Feldspar. J. Phys. Chem. C 2019, 123, 24520-24532.

1260

(69) Zhang, L.; Lüttge, A. Aluminosilicate Dissolution Kinetics: A 1261 General Stochastic Model. J. Phys. Chem. B 2008, 112, 1736-1742. 1262 